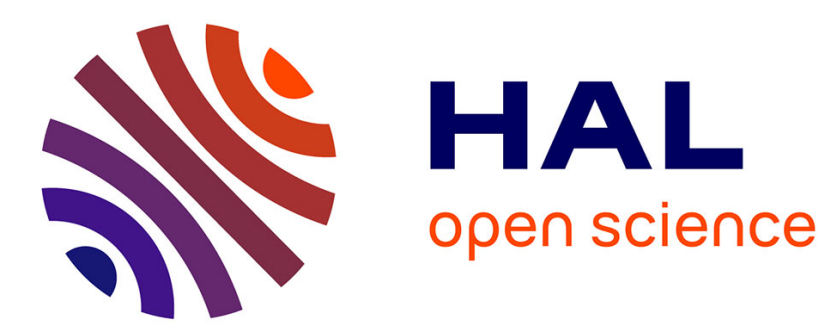

\title{
THE FRACTURE OF DIAMOND COATINGS BY HIGH VELOCITY SAND EROSION
}

Robert Jk Wood, David Wheeler

\section{To cite this version:}

Robert Jk Wood, David Wheeler. THE FRACTURE OF DIAMOND COATINGS BY HIGH VELOCITY SAND EROSION. Philosophical Magazine, 2009, 89 (03), pp.285-310. 10.1080/14786430802616557 . hal-00514004

\section{HAL Id: hal-00514004 \\ https://hal.science/hal-00514004}

Submitted on 1 Sep 2010

HAL is a multi-disciplinary open access archive for the deposit and dissemination of scientific research documents, whether they are published or not. The documents may come from teaching and research institutions in France or abroad, or from public or private research centers.
L'archive ouverte pluridisciplinaire HAL, est destinée au dépôt et à la diffusion de documents scientifiques de niveau recherche, publiés ou non, émanant des établissements d'enseignement et de recherche français ou étrangers, des laboratoires publics ou privés. 


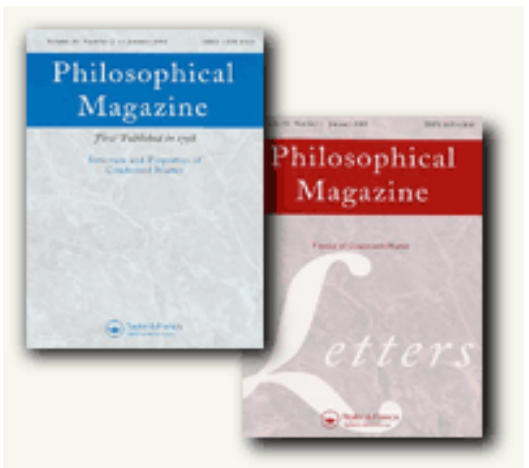

\section{THE FRACTURE OF DIAMOND COATINGS BY HIGH VELOCITY SAND EROSION}

\begin{tabular}{|r|l|}
\hline Journal: & Philosophical Magazine \& Philosophical Magazine Letters \\
\hline Manuscript ID: & TPHM-08-Jul-0264.R1 \\
\hline Journal Selection: & Philosophical Magazine \\
\hline Date Submitted by the \\
Author: & 09-Nov-2008 \\
\hline Complete List of Authors: & $\begin{array}{l}\text { Wood, Robert; University of Southampton, School of Engineering } \\
\text { Sciences } \\
\text { Wheeler, David; University of Southampton, School of Engineering } \\
\text { Sciences }\end{array}$ \\
\hline Keywords: & $\begin{array}{l}\text { damage, defects, diamond, mechanical behaviour, microscopy, } \\
\text { surface engineering, tribology, wear }\end{array}$ \\
\hline Keywords (user supplied): & erosion, impact damage \\
\hline
\end{tabular}

\section{今 scholarONE" \\ Manuscript Central}




\title{
THE FRACTURE OF DIAMOND COATINGS BY HIGH VELOCITY
} SAND EROSION

\author{
D.W. Wheeler, R.J.K. Wood* \\ national Centre for Advanced Tribology at Southampton (nCATS), School of Engineering \\ Sciences, \\ University of Southampton, Highfield, Southampton, SO17 1BJ, U.K.
}

\begin{abstract}
This paper describes a study of the behaviour of diamond coatings when subjected to solid particle erosion from sand particles. The coatings were deposited by chemical vapour deposition (CVD) onto tungsten substrates and tested using a high velocity air-sand erosion test facility. The erosion tests were conducted using particle impact velocities of between 33 and $268 \mathrm{~m} \mathrm{~s}^{-1}$. Examination of the eroded test specimens showed that the principal damage features observed were circumferential cracks and pin-holes. Comparison with Hertz impact theory revealed that the measured circumferential crack diameters were more than double the predicted Hertzian contact diameter. Moreover, a trend of increasing circumferential crack diameter with coating thickness, which is not predicted by Hertz, was found. Instead, the crack diameters showed good agreement with those predicted by the theory of stress wave reinforcement, which is more commonly associated with liquid impact damage of brittle materials. During impact, the bulk compression and shear waves are reflected at the rear surface of debonded regions of the coating to return to the front surface and reinforce the Rayleigh surface wave, which generates a tensile stress. Where this stress exceeds the local tensile strength of the coating, a ring of cracks surrounding the area of impact is created. The results from the present study therefore suggest that stress wave reflection is responsible for the formation of the cracks at locally debonded regions of the coating. This hypothesis was supported by images acquired using scanning acoustic microscopy, which showed that circumferential cracks and pin-holes were only found on areas of the coating that had become delaminated by multiple particle impacts during the erosion tests.
\end{abstract}

Keywords: diamond; erosion; impact damage; surface engineering; tribology.

$*=$ corresponding author. 


\section{Introduction}

The high hardness and strength of diamond make it an attractive option for components in a wide range of engineering, and in particular tribological, applications. The advent of diamond coatings produced by chemical vapour deposition (CVD) has significantly increased the number of potential applications. The last two decades have witnessed significant improvements in deposition rates to such an extent that high-power microwave deposition systems can produce CVD diamond over areas of up to $200 \mathrm{~mm}$ diameter and $1 \mathrm{~mm}$ in thickness [1].

CVD diamond has found use in many applications including radiation detectors, field emission displays, fibres for composites, as well as micro electro-mechanical systems (MEMS) and sensors [1]. In the electronics industry the high thermal conductivity of CVD diamond has led to its use as a substrate material for the dissipation of heat by high power micro- or opto-electronic devices such as laser diodes. Mechanical applications include wheel dressing and tools for machining metal matrix composites, where they have exhibited lower wear rates and produced better surface finishes than polycrystalline diamond (PCD) composites. CVD diamond has also been used in surgical blades in ophthalmology, where they generate lower cutting forces than stainless steel, which leads to less tissue damage. It has also been the subject of development programmes for use in mechanical seals [2], infrared-transmitting windows and domes for aircraft [3] and in choke valves used in the offshore oil industry [4], where its high erosion resistance has the potential to deliver significant increases in valve operating life.

If the applications of diamond coatings are to be extended to new wear-resistant components it is vital to understand the mechanisms by which the coatings become degraded in erosive environments. Solid particle erosion studies of diamond coatings and free-standing diamond [5-7] have shown that the major damage features observed are ring cracks, the formation of which can be explained by the Hertz impact theory [8]; further details can be found in Appendix 1. These cracks are nucleated at favourably-orientated surface flaws by the tensile stress generated by particle impact just outside the radius of contact where the stress is at its maximum. Once nucleated, the cracks propagate around the contact circle to form a surface ring crack [9]. Although usually associated with impact from spherical particles, Hertzian ring cracks have also been observed in studies where the shapes of the impacting particles deviate significantly from that of a perfect sphere. In another study by the present authors [10] ring cracks were observed on CVD boron phosphide coatings impacted by sub-rounded 355-500 $\mu \mathrm{m}$ silica sand at a velocity of $33 \mathrm{~m} \mathrm{~s}^{-1}$, the diameters of which showed good agreement with those predicted by Hertz. However, previous publications by the authors [11-13] have reported on the circumferential crack and pin-hole damage observed in diamond coatings following impacts from sand particles at high velocity. They also showed that the measured circumferential crack diameters did not agree with the predicted Hertzian contact diameter. Therefore, it is necessary to identify an alternative mechanism responsible for their formation. This is the subject of the present paper.

\section{Experimental Details}

The diamond coatings were deposited by chemical vapour deposition onto tungsten substrates and lapped to a surface roughness $\left(R_{a}\right)$ of $0.2 \mu \mathrm{m}$; no details of the deposition process were supplied. The diamond was mechanical grade "black" diamond and was, therefore, not transparent. The thickness range of the diamond films were between $33 \mu \mathrm{m}$ and $90 \mu \mathrm{m}$. The coated specimens were $50 \mathrm{~mm}$ diameter and $6 \mathrm{~mm}$ thick and were tested in the as-received 
condition. Figure 1 shows an electron micrograph of an untested diamond coating while Table 1 lists the relevant properties of the coatings [7,14,15].

The erosion tests were conducted in a high velocity air-sand erosion rig, details of which can be found elsewhere [16]. The erodent was a blend of three commercially available silica sands: the blend was used to reproduce the size distribution found in the North Sea Forties oil field. The morphology of the sand varied from angular to sub-rounded with the majority of the sand being within the range of 63 to $600 \mu \mathrm{m}$; the average diameter was $194 \mu \mathrm{m}$.

In the erosion tests particle velocities of between 33 and $268 \mathrm{~m} \mathrm{~s}^{-1}$ were employed; the velocities were calibrated using high-speed photography. The sand feed rate was $6 \mathrm{~g} \mathrm{~min}^{-1}$, which corresponded to a particle flux of $0.5 \mathrm{~kg} \mathrm{~m}^{-2} \mathrm{~s}^{-1}$. This flux rate is below the level at which particle-particle interactions begin to reduce the erosion rate significantly [17]. The stand-off distance, from the end of the nozzle to the diamond surface, was $30 \mathrm{~mm}$. In all cases the angle of incidence of the particles with the surface was $90^{\circ}$ as the maximum erosion rate of brittle materials occurs at this angle. The diamond coatings were examined before, during and after the erosion tests using both optical and scanning electron microscopy.

\section{Results}

The erosion behaviour of diamond coatings can be divided into three stages, which are illustrated in Figure 2, which shows a graph of cumulative mass loss (CML) against time for a $46 \mu \mathrm{m}$ diamond coating subjected to $63-600 \mu \mathrm{m}$ sand impinging on the coating at a mean velocity of $268 \mathrm{~m} \mathrm{~s}^{-1}$. In the first stage, the most prominent areas of the coating are removed by micro-chipping of grains by transgranular cracking, resulting in the ejection of fragments of the coating; in general, this stage does not account for a significant percentage of the coating life. When the most prominent areas have been removed, a slowing of the rate of coating removal is observed, which marks the onset of stage two, during which the rate of coating removal corresponds to the steady state erosion rate. A previous study by the present authors [18] found that diamond exhibited a steady state erosion rate of more than an order of magnitude lower than other hard materials such as cemented tungsten carbide. The third and final stage of the erosion process is failure of the coating, which often occurs catastrophically by delamination at the coating-substrate interface.

Examination of the eroded surfaces of the diamond coatings revealed that elastic-plastic radial and lateral cracks, which have often been reported in erosion studies of other brittle materials [10], were not seen in the eroded diamond coatings. The reason for this is the disparity in mechanical properties between target and erodent. As can be seen from Table 1, the hardness and elastic modulus of the CVD diamond coatings are considerably greater than those of the silica sand erodent. With such an erodent-target combination it is therefore likely that the erodent will suffer greater damage on impact than the target material. Sieving of the sand after the erosion tests revealed that the mean particle size had reduced by up to $67 \%$. However, of more significance than the micro-chipping are the damage features that will now be discussed in greater detail below.

During the steady state erosion stage, the micro-chipping was often augmented by the nucleation of circumferential cracks and pin-holes, examples of which are shown in Figures 3 and 4. Previous work by the authors [19] has shown the sequence of damage accumulation in diamond coatings subjected to impact from sand particles. The following steps occur in the development of a pin-hole: 
- Formation of a circumferential crack;

- Initiation of damage in the central region within the circumferential crack;

- Growth of the central damaged region both vertically (towards the coating-substrate interface) and laterally (towards the circumferential crack).

These circumferential cracks and pin-holes were usually found at isolated locations of the coating and only rarely were two cracks found to overlap with each other. Many of the newly formed circumferential cracks were discontinuous rather than a complete ring.

The results showing the effect of particle velocity on circumferential crack diameter can be seen in Table 2 and Figure 5, which plots the mean circumferential crack diameters as a function of velocity for two sets of coatings, $46 \mu \mathrm{m}$ and $60 \mu \mathrm{m}$ in thickness; the data for a 39 $\mu \mathrm{m}$ coating tested at $63 \mathrm{~m} \mathrm{~s}^{-1}$ is also included. For comparison, the Hertzian contact diameter is also plotted. The graph shows that there is a slight increase (by between 20 and $60 \mu \mathrm{m}$ ) in average crack diameter with velocity over the range of 63 to $268 \mathrm{~m} \mathrm{~s}^{-1}$. The cause of the greater mean diameter at $232 \mathrm{~m} \mathrm{~s}^{-1}$ than that at $268 \mathrm{~m} \mathrm{~s}^{-1}$ is not, at present, clear. Nevertheless, it can be seen that the circumferential crack diameters are between two and four times the Hertzian contact diameter.

Another effect of particle velocity was that the time at which the first circumferential cracks were observed was strongly dependent on the particle impact velocity. At the highest velocity, $268 \mathrm{~m} \mathrm{~s}^{-1}$, cracks were first observed on the $46 \mu \mathrm{m}$ coating after 1 hour. On the $46 \mu \mathrm{m}$ coating tested at $148 \mathrm{~m} \mathrm{~s}^{-1}$ this figure had increased to 3 hours while at $63 \mathrm{~m} \mathrm{~s}^{-1}$ cracks were not observed on the $40 \mu \mathrm{m}$ coating until 12 hours had elapsed. In the test of a $40 \mu \mathrm{m}$ coating at 33 $\mathrm{m} \mathrm{s}^{-1}$ no cracks were observed after 20 hours of particle impacts. From a mechanistic standpoint, in comparing the time elapsed before circumferential cracks or pin-holes are observed for the different velocities it is more instructive to compare the tests in terms of number of particle impacts. The number of impacts per Hertzian impact zone $N($ Hertz) was calculated for each test condition using equation A9 listed in the Appendix and the results also listed in Table 3. It can be seen that even at the highest velocity employed in the present tests more than 3800 particle impacts are required before the first circumferential cracks and pin-holes are observed. This is in contrast to the findings of other studies, for example Feng et al [5], in which ring cracks were observed within 10 seconds on $15 \mu \mathrm{m}$ diamond coatings on $\mathrm{SiC}$ eroded at $34 \mathrm{~m} \mathrm{~s}^{-1}$. Moreover, another study by the present authors [20] observed ring cracks in free-standing $600 \mu \mathrm{m}$ diamond brazed to WC substrates when impacted by cubooctahedral diamond grit erodent at a $268 \mathrm{~m} \mathrm{~s}^{-1}$ for only 1 second.

\section{Discussion}

\subsection{Comparison of crack diameters with Hertz impact theory}

Using the formulae listed in the Appendix and the mechanical properties of the silica sand and diamond listed in Table 1, the contact conditions for the particle velocities used in the tests were calculated using Hertz impact theory. The predicted conditions are listed in Table 3. It can be seen that high pressures are generated by the particle impacts, which result in high values of tensile stress, $\sigma_{m}$, at the edges of the contact radii. They range from $2.6 \mathrm{GPa}$ at $33 \mathrm{~m}$ $\mathrm{s}^{-1}$ to $6.0 \mathrm{GPa}$ at $268 \mathrm{~m} \mathrm{~s}^{-1}$. These values all exceed the tensile strength of CVD diamond; although the tensile strength of the coatings used in the present study is unknown, other studies [5,21] have recorded a value of $1.4 \mathrm{GPa}$ using static indentation tests of $15 \mu \mathrm{m}$ thick diamond coatings. The tensile strength of CVD diamond has been observed to decrease with increasing thickness [22] owing to the greater size of microstructural defects: therefore, it is 
probable that the tensile strengths of the coatings used in the present study were significantly less than $1.4 \mathrm{GPa}$. However, the high incidence of particle fragmentation on impact means that the real value of $\sigma_{m}$ is likely to be significantly lower than the calculated value.

The Hertzian approach assumes that the elastic energy of the two bodies acquired during the collision processes is entirely reversible, the approach and recessional velocities of impact are identical making the coefficient of restitution unity [23]. However, a study by Wheeler [24] using high speed photography found that at a velocity of $133 \mathrm{~m} \mathrm{~s}^{-1}$, the highest velocity used in that study, the coefficient of restitution was 0.2. This significant departure from a coefficient of restitution of 1.0 was attributed to the extensive fragmentation of the sand on impact. Although it was not possible to measure the coefficient of restitution at a velocity of $268 \mathrm{~m} \mathrm{~s}^{-1}$, extrapolation of the data to velocities higher than $133 \mathrm{~m} \mathrm{~s}^{-1}$ suggested that it may be as low as 0.1 . This marks another departure from the assumptions inherent in the Hertzian approach.

Table 3 also compares the measured circumferential crack diameters with the calculated Hertzian contact diameters. It can be seen that significant discrepancies exist between the two sets of values. The mean contact diameter for a $194 \mu \mathrm{m}$ diameter particle (the average diameter of the sand used in the sand blend) impacting on the diamond surface at $268 \mathrm{~m} \mathrm{~s}^{-1}$ has been calculated to be $76 \mu \mathrm{m}$. However, this does not agree with the measured values taken from the eroded coatings of $193 \mu \mathrm{m}$ for the $46 \mu \mathrm{m}$ thick coating or $281 \mu \mathrm{m}$ for the $60 \mu \mathrm{m}$ coating. One possible explanation for this lack of agreement is that friction between the sand particle and the diamond surface (arising from differences in elastic properties between indenter and target) has increased the diameter at which the maximum tensile stress is located. Johnson et al [25] have shown that this phenomenon can increase the measured ring crack diameter by up to $30 \%$ greater than the predicted value. However, as can be seen in Figures 2 and 3 for example, the circumferential crack diameters are more than double the predicted figure. Furthermore, the predominantly angular morphology of the sand particles used in this study will result in a smaller contact radius than that predicted by Hertz.

One of the complications in comparing the circumferential crack diameters with Hertz theory is the wide size distribution of the sand used in the present study which, although replicating service conditions, complicates the task of determining the contact conditions. The majority of the sand grains are within the range 63-600 $\mu \mathrm{m}$. In order to study the effect of a narrower particle distribution, two lapped coatings of $40 \mu \mathrm{m}$ and $60 \mu \mathrm{m}$ in thickness were tested at the same velocity using sand that had been sieved to ensure that all particles had diameters within the range $355-500 \mu \mathrm{m}$; the average diameter of the sieved sand was $442 \mu \mathrm{m}$, which was determined by measurements from electron micrographs of the sand. The contact conditions are listed in Table 4. The crack diameters on these coatings were within the same range as those observed in the tests using the sand with the wider size distribution. The mean crack diameters measured from the $40 \mu \mathrm{m}$ and $60 \mu \mathrm{m}$ coatings impacted by the $355-500 \mu \mathrm{m}$ sand were $178 \mu \mathrm{m}$ and $269 \mu \mathrm{m}$ respectively. The latter figure is close to the mean diameter of 281 $\mu \mathrm{m}$ for the $60 \mu \mathrm{m}$ coating impacted by the $63-600 \mu \mathrm{m}$ sand. The trend of increasing crack diameter with coating thickness is therefore replicated when a narrower size distribution of sand is used as the erodent.

Another factor that could influence the crack diameter is the velocity of the sand particles. The mean velocity of the tests using the sieved $355-500 \mu \mathrm{m}$ sand was $268 \mathrm{~m} \mathrm{~s}^{-1}$, although particle velocities of between 253 and $298 \mathrm{~m} \mathrm{~s}^{-1}$ were measured during calibration at this particular air flow rate. Assuming a $500 \mu \mathrm{m}$ particle travelling at $253 \mathrm{~m} \mathrm{~s}^{-1}$ and a $355 \mu \mathrm{m}$ sand 
particle travelling at $298 \mathrm{~m} \mathrm{~s}^{-1}$ the Hertz impact conditions were recalculated to predict the contact diameter. Under these conditions, the Hertzian contact diameters are predicted to be $190 \mu \mathrm{m}$ and $144 \mu \mathrm{m}$ respectively. Although these figures are within the range of crack diameters measured on the $40 \mu \mathrm{m}$ coating, they are significantly smaller than the crack diameters from the $60 \mu \mathrm{m}$ coating. Furthermore, this still does not explain the increase in crack diameter with coating thickness.

Another influence that could be modifying the stress field to give larger contact diameters than predicted is the tungsten substrate. However, both theory and experiment have shown that for a hard coating of thickness $C_{T} / a_{m}=0.5$, and where the elastic modulus of the coating is approximately three times that of the substrate, the measured contact size is almost the same as that for a half space of the coating material [26]. In the present study, the elastic modulus of the diamond coating is $1157 \mathrm{GPa}$ [24], making it approximately 2.9 times that of the tungsten substrate (400 GPa) [27]. As can be seen in Tables 3 and 4 , the $C_{T} / a_{m}$ ratio is between 0.5 and 2.4. For this reason the effect of the substrate can be ignored in the present case. Furthermore, surface profilometry of the circumferential cracks revealed no deflection in the growth surface of the coating, which suggests that the substrate has not undergone any plastic deformation.

A further impediment to ring crack formation is the residual stress present in the coating, which arises from the mismatch in thermal expansion coefficient between the coating and substrate and will affect the stress field as well as the contact conditions. The thermal expansion coefficient at ambient temperature of the tungsten substrate is $4.5 \times 10^{-6} \mathrm{~K}^{-1}$ [27], which is more than four times that of diamond $\left(1.0 \times 10^{-6} \mathrm{~K}^{-1}\right)$ [1]. As a result, the residual stress in the coating will be compressive owing to the greater contraction of the substrate on cooling to ambient temperature following deposition, which typically takes place at temperatures in the region of between 800 and $1000^{\circ} \mathrm{C}$ (the process conditions used in the deposition of the present coatings are not known to the authors).

The effect of the compressive stress is to increase the minimum fracture load (and therefore the tensile stress at the contact edge) required to form Hertzian ring cracks. Before this higher load is reached the fracture of the sand particles may occur, thereby preventing that load from being attained. Roberts et al [28,29] have investigated the effect of compressive residual stress on the fracture load in a Hertz indentation test indenting glass with a $10 \mathrm{~mm}$ diameter glass ball. They found that as the surface compressive stress increased from 0 (nominally "stress free") to $500 \mathrm{MPa}$ the minimum fracture load increased by more than an order of magnitude. In the present study the average residual stress in the diamond coatings has been estimated from Raman peak shift data to be approximately $870 \mathrm{MPa}$ [24]. Therefore, the increase in load required to initiate Hertzian ring cracking compared with the "stress free" case, as well as the probability of particle fracture, is likely to be even greater than an order of magnitude.

In summary, there are a number of reasons why Hertz impact theory cannot explain the formation of these circumferential cracks. These include extensive particle fragmentation, predominantly angular particle morphology and the apparent dependence of circumferential crack diameter on coating thickness. Therefore, in the absence of any agreement between Hertz theory and the experimental results, it is necessary to consider alternative damage mechanisms. 


\subsection{Use of stress wave theory to explain circumferential crack formation}

One alternative mechanism by which these circumferential cracks may have been formed is by stress waves that are generated in the target material by impact from the particles. This theory was first proposed by Bowden and Field [30] to explain liquid impact damage of brittle materials: for thin targets stress wave reflection from the rear surface could cause fracture at the impacted surface. More recently, Coad and Field [31] found a trend of crack diameter vs. target thickness for free-standing CVD diamond of between 0.5 and $2.5 \mathrm{~mm}$ in thickness. In the present study, it was thought that the circumferential cracks could have been formed by stress wave reflections at locally delaminated regions of the coating. Although it might be thought that the impact conditions associated with liquid droplets would differ significantly from impact by solid particles, impact experiments by Telling et al [6] using ice and nylon particles on a brittle material - polymethylmethacrylate (PMMA) - generated damage features of similar appearance to those from liquid impact. The particle degradation in the present study, both by plastic flow and fragmentation, suggests that the impact conditions may not be wholly unrelated to impact either from soft particles or liquid droplets. Therefore, in view of the resemblance in appearance between the liquid impact damage and the circumferential cracks in the present case, it merits further investigation.

\subsubsection{Theory of stress wave reflection and reinforcement}

There are two possible ways by which reflected bulk waves can reinforce Rayleigh surface waves; these are shown in Figure 6. The first is when a compression wave is reflected and returns as a tensile wave. Alternatively, a compression wave can undergo mode conversion to a shear wave, or vice versa, before returning to the front surface. When the tensile Rayleigh wave is augmented at the surface by a returning tensile wave the resultant stress may be sufficient to generate cracking in the front surface of the material. The high stress wave velocity and low attenuation in diamond means that, in the present case, this may be significant in the generation of circumferential cracks. Coad and Field [31] found good agreement between measured circumferential crack radius and the theoretical radius calculated using this approach. However, it was not known whether this theory would be applicable in the case of thinner coatings on substrates, under impact by solid particles.

On the basis of the two stress wave reflection scenarios, the radii of the circumferential cracks were predicted by Bowden and Field [30] and later extended by Seward et al [32]. The ratios of the compression and shear wave velocities are given by:

$$
\frac{c_{1}}{c_{2}}=\left\{\frac{2(1-v)}{(1-2 v)}\right\}^{1 / 2}=1.47
$$

where $c_{1}$ is the compression wave velocity and $c_{2}$ the shear wave velocity, which in diamond are $18,235 \mathrm{~m} \mathrm{~s}^{-1}$ and $12,400 \mathrm{~m} \mathrm{~s}^{-1}$ respectively; the Rayleigh surface wave velocity $\left(c_{R}\right)$ is $11,160 \mathrm{~m} \mathrm{~s}^{-1}$. A Poisson's ratio $(v)$ of 0.07 was used in the velocity calculations. Using this information, it is possible to predict the radii at which these two reinforcements occur, $y_{l}$ and $y^{\prime}$, as a function of target thickness, $x_{t}$. A compression wave reflected as a tensile wave will be reinforced by the Rayleigh wave at a radius $y_{1}$ while a compression wave reflected as a shear wave will be reinforced at a radius $y^{\prime}$. The calculated radii are:

$\frac{y_{1}}{x_{\text {th }}}=1.52$

and 
$\frac{y^{1}}{x_{t h}}=2.14$

If stress wave reinforcement occurs, and circumferential cracks are formed in the coating surface, the diameters of these cracks will be:

$d_{1}=2 y_{1}+\Delta y$

and

$d^{1}=2 y^{1}+\Delta y$

$\Delta y$ is the diameter over which the high pressure phase exists and is defined as:

$$
\Delta y=\frac{2 R V}{c_{e}}
$$

where $R$ is the mean radius, $V$ is the particle impact velocity and $c_{e}$ the speed of sound of sound in the silica sand erodent, the value of which $\left(6079 \mathrm{~m} \mathrm{~s}^{-1}\right)$ was calculated using equation (7):

$$
c_{e}=\sqrt{\left(\frac{E}{\rho} \cdot \frac{1-v}{(1-2 v)(1+v)}\right)}
$$

The values of elastic modulus $(E)$, density $(\rho)$ and Poisson's ratio $(v)$ for silica $\left(\mathrm{SiO}_{2}\right)$ used in calculating $c_{e}$ can be found in Table 1. For a $194 \mu \mathrm{m}$ diameter sand particle impacting on diamond at $268 \mathrm{~m} \mathrm{~s}^{-1} \Delta y$ is $9 \mu \mathrm{m}$ while for a $442 \mu \mathrm{m}$ diameter particle at the same velocity $\Delta y$ is $20 \mu \mathrm{m}$. According to Seward et al [32] the dominant reinforcement for materials with low Poisson's ratios should be $y$ '. Therefore, the circumferential crack diameters were compared with the diameter at which this reinforcement occurs. In the present paper, the term "target thickness", $x_{t h}$, is the same as coating thickness, $C_{T}$.

4.2.2 Effect of coating thickness on circumferential crack diameter

The effect of coating thickness on circumferential crack diameter in diamond coatings subjected to impact from sand particles at a velocity of $268 \mathrm{~m} \mathrm{~s}^{-1}$ can be seen in Table 5. It shows that the mean measured crack diameter of the thickest coating $(90 \mu \mathrm{m})$ is approximately 2.4 times larger than that of the thinnest $(33 \mu \mathrm{m})$. A similar relationship is seen between grain size and coating thickness, in which the grain size generally increases with thickness. However, as can also be seen in Table 5, the crack diameters are between five and ten times the grain size of the coatings. Therefore, the cracks encompass several grains and their paths do not appear to be influenced by grain boundaries and the pin-holes are formed by the removal of several grains rather than by the ejection of individual grains.

The dependence of circumferential crack diameter on coating thickness was compared with the predicted stress wave reinforcement diameter, $d$ ', and is shown in Figure 7. It can be seen 
that there is good agreement between the predicted and measured diameters, although it should be remembered that the measured circumferential crack diameters constitute a range of values. Although this may be thought to be due to the wide range in the size of the eroding particles, it has already been seen that no significant differences were observed between the coatings eroded by the $63-600 \mu \mathrm{m}$ sand and the sieved $355-500 \mu \mathrm{m}$ sand. It is more likely that the variations in crack diameter seen in each coating are due to factors such as scattering of bulk waves at the coating-substrate interface by grain-boundary porosity; the calculation of the stress wave reinforcement diameter ignores such effects and assumes a perfect interface. The columnar grains and grain boundaries could also scatter the waves, as may the presence of residual stresses and variations in Poisson's ratio within the coating. In the case of the latter parameter, the calculations employed an aggregate value of 0.07 , though it is known to vary with crystallographic orientation from 0.01 to greater than 0.2 [33]. Moreover, the increasing grain size with thickness increases the possibility of large grains behaving as single crystals. Despite these uncertainties, the good agreement between theory and experiment does suggest that the reflection and reinforcement of stress waves at locally debonded regions of the coating could be responsible for the formation of the circumferential cracks.

\subsubsection{Circumferential crack formation}

As the circumferential cracks appear to resemble those generated by liquid impact, the impact pressure, $P_{i}$, the so-called "water hammer pressure", can be calculated using the following expression:

$$
P_{i}=\rho_{e} c_{e} V
$$

where $\rho_{e}$ is the density of the erodent, $c_{e}$ the speed of sound in the erodent and $V$ the impact velocity. The values used in this calculation were: $\rho=2650 \mathrm{~kg} \mathrm{~m}^{-3} ; C=6079 \mathrm{~m} \mathrm{~s}^{-1} ; V=268$ $\mathrm{m} \mathrm{s}^{-1}$. Using these values an impact pressure of $4.3 \mathrm{GPa}$ is calculated. This figure, while less than the predicted Hertzian tensile stress of $6.0 \mathrm{GPa}$ is still substantial. However, the true pressure is likely to be lower. A more realistic figure can be obtained using a modified form of the above expression given by Jackson and Field [34]. This states that the peak height of the simplified triangular wave pulse is:

$$
\sigma_{\max }=\beta \rho C V
$$

Where $\beta$ is a function dependent on Poisson's ratio, $v$, of the target material, and is defined as:

$$
\beta=\frac{1}{2}(1-2 v)
$$

Assuming $v=0.07$ for diamond this gives a value of $\sigma_{\max }$ of $1.81 \mathrm{GPa}$. However, the magnitude of the Rayleigh wave will decay with radius from the origin proportional to $r^{-1 / 2}$; therefore, at a particular distance from the centre of impact its magnitude can be calculated. For a $60 \mu \mathrm{m}$ diamond coating, where the radius of reinforcement is $133 \mu \mathrm{m}, \sigma_{\max }$ will have declined from $1.81 \mathrm{GPa}$ to approximately $160 \mathrm{MPa}$. For simplicity, this calculation ignores any contribution from compression or shear waves reflected from the delaminated interface as well as any Rayleigh waves generated by impacts from adjacent particles which may either augment or diminish this stress. This figure can now be used to establish whether such a stress is of sufficient magnitude to cause fracture in the diamond. According to Pickles [22], the critical flaws controlling fracture in CVD diamond are of similar size to the grains. On this 
basis, for a $60 \mu \mathrm{m}$ diamond coating the critical flaw would be expected to be of the order of $27 \mu \mathrm{m}$. Using this figure, the stress, $\sigma$, required to activate a flaw of that size can be determined using the following equation [34]:

$$
\sigma=\frac{K_{1 c}}{1.3 \sqrt{\pi c_{c r}}}
$$

Assuming a fracture toughness, $K_{l c}$, of $6.0 \mathrm{MPa} \sqrt{\mathrm{m}}$ and a critical flaw size, $c_{c r}$, of $27 \mu \mathrm{m}$, a stress of $501 \mathrm{MPa}$ is required to activate the flaw. Thus the Raleigh surface stress figure is less than one-third of the stress required to activate a flaw $27 \mu \mathrm{m}$ in size and requires reinforcement from the reflected bulk waves in order to form circumferential cracks in the coating surface. Moreover, the circumferential cracks in the eroded coatings are not the product of a single impact but several thousand individual impacts. It is clear that further work is necessary to understand this complex issue, for example by finite element modelling.

\subsection{Scanning Acoustic Microscopy}

The opaque nature of the diamond prevents the observation of sub-surface damage. Therefore, in order to detect this damage a technique such as scanning acoustic microscopy is needed. Scanning acoustic microscopy (SAM) has been used for the detection of porosity in thermal sprayed ceramic coatings [35], delamination of polycrystalline diamond bonded to tungsten carbide [36], and the identification of different phases in metal-composite coatings [37]. It has also been used to determine the residual stress of coatings as well as mechanical properties such as elastic modulus [37,38] and for the evaluation of surface damage in brittle materials $[39,40]$.

Both untested and eroded coatings were examined using a Sonoscan C-SAM series D-9000 scanning acoustic microscope. Equipped with a $230 \mathrm{MHz}$ transducer, it possesses a spatial resolution of $10 \mu \mathrm{m}$ in the $\mathrm{x}$ and $\mathrm{y}$ directions, and $0.1 \mu \mathrm{m}$ in the $\mathrm{z}$ (vertical) direction. The samples were immersed in a tank containing distilled water to provide a coupling medium between the probe and the sample and the probe was scanned across the sample at a constant rate of $25 \mathrm{~mm} \mathrm{~s}^{-1}$ to create the acoustic image. The acoustic beam was focused at the growth surface of the coating; the stand-off distance between the probe and sample corresponded to the focal length of the transducer in water: for a $230 \mathrm{MHz}$ probe this distance was $9.5 \mathrm{~mm}$. An electronic gate was used to select echoes from a specific level within the sample to be used for imaging purposes. The width of the gate was $0.05 \mu \mathrm{s}$ : as the compression wave velocity in diamond is $18,235 \mathrm{~m} \mathrm{~s}^{-1}$, this corresponds to a depth of $0.9 \mathrm{~mm}$. Echoes from features located outside this region were ignored. The images generated by the acoustic microscope are in the form of maps showing the variation in amplitude of the acoustic echo. In general, ultrasonic waves cannot travel through a vacuum. Therefore, regions where the two materials are not perfectly bonded can be identified by the near-total reflection of the ultrasound.

Figure 8 shows an acoustic image of an untested diamond coating. The scale on the left of the figures relates to the amplitude of the acoustic echo. The lack of variation in the colour of the image indicates that there are no areas where the coating is debonded. Grain boundary porosity is known to be present in CVD diamond coatings at the coating-substrate interface [41]. However, these pores are generally less than $10 \mu \mathrm{m}$ in size and are therefore below the spatial resolution of the acoustic microscope. Nevertheless, there does not appear to be any gross delamination of the coating in its untested condition. 
In contrast, the image in Figure 9 shows a SAM image taken from a $60 \mu \mathrm{m}$ diamond coating eroded by $63-600 \mu \mathrm{m}$ sand for 5 hours at $268 \mathrm{~m} \mathrm{~s}^{-1}$. The white areas, indicative of the highest amplitude reflections, are the areas where the coating has delaminated. These delaminated regions vary between 75 and $634 \mu \mathrm{m}$ with an average diameter of $271 \mu \mathrm{m}$. The measured distances between the delaminated regions was found to be between 84 and $890 \mu \mathrm{m}$, the average distance being $364 \mu \mathrm{m}$. However, more significant than the areas of delamination are the pin-holes, which are denoted by the circular dark features. It is significant that these features were surrounded by areas of delamination, which suggests that pin-holes are formed on locally debonded regions. One of these areas where a pin-hole is located can be seen in Figure 9. The delaminated region on which it is located is approximately $510 \mu \mathrm{m}$ in diameter.

The circumferential cracks and pin-holes are not seen on well-bonded regions of the coating because there is insufficient reflection of the compression and shear waves at the coatingsubstrate interface. The amount of energy transmitted or reflected at the interface between the coating and substrate is dependent on the difference in acoustic impedance, $Z$, which is the product of wave velocity $\left(c_{1}\right)$ and density $(\rho)$ :

$Z=\rho c_{1}$

The proportion of reflected energy at the interface is described by the reflection coefficient, $R C$ :

$R C=I \frac{Z_{2}-Z_{1}}{Z_{2}+Z_{1}}$

where $I$ is the incident energy and $Z_{1}$ and $Z_{2}$ the acoustic impedance of the coating and substrate respectively. Using equation (13) it has been calculated that the reflection coefficient for a wave travelling from diamond into tungsten is approximately 0.22 , i.e. only $22 \%$ of the incoming energy will be reflected at the interface. In contrast, near-total reflection will occur at a region where the coating is not bonded to the substrate. It should be noted that this hypothesis is based on a wave travelling at normal incidence to the interface and therefore ignores incidence angles other than $90^{\circ}$. Moreover, it also assumes a perfect interface, with no defects such as porosity present, which may cause scattering of the waves. Nevertheless, this helps to explain why circumferential cracks are only observed on debonded regions of impacted coatings.

\subsection{Examination of coating nucleation surface}

The value of the SAM images would be enhanced if corroborated by actual microstructural observations of these sub-surface damage features. This was achieved by dissolving the tungsten substrate of a $60 \mu \mathrm{m}$ diamond coating eroded by $63-600 \mu \mathrm{m}$ sand for 5 hours at 268 $\mathrm{m} \mathrm{s}^{-1}$. The substrate was dissolved by immersion in a solution of $\mathrm{HF}$ and $\mathrm{HNO}_{3}$ in a 2:1 ratio (by volume) to leave a free-standing film. Electron micrographs of the nucleation surface of the coating are shown in Figures 10 to 12. The white areas in these figures, which were identified as tungsten by energy dispersive spectroscopy (EDS), denote the presence of a thin layer of residual tungsten from the substrate which had not been completely removed by the acid solution. A transverse examination of this specimen revealed that the tungsten layer was approximately $10 \mu \mathrm{m}$ in thickness.

Examination of the nucleation surface of the diamond film using optical and electron microscopy revealed no evidence of any damage in the regions of the coating outside the area 
of particle impingement. As shown in Figure 10, remnants of the substrate remained adhered to the nucleation surface of the coating. In contrast, Figures 11 and 12, which were taken from the region of the coating subjected to particle impingement, reveal the presence of extensive damage in the centre of the area of particle impingement, declining in extent further away from the centre of the specimen. Figure 11 shows a small area of tungsten-free diamond present on the nucleation surface of the diamond film. The size of this feature, approximately $70 \mu \mathrm{m}$ in length, is of a similar size to the smallest delaminated areas in Figure 9. The figure also shows a network of large interconnecting cracks, many of which can be seen propagating from the tungsten-free areas. These cracks are too small to be detected by acoustic microscopy. These cracks are thought to have been caused by the shear stresses that are generated by the impacting particles. In previous work by the present authors [41], a taper polished section of an eroded coating showed that, in addition to debonding at the coatingsubstrate interface, cracking could be seen extending from the interface into the substrate to a depth of approximately $10 \mu \mathrm{m}$. Therefore, it is likely that it is this cracking that can be seen in Figure 11. The development of coating debonding is discussed in Section 4.5.

No circumferential cracks, partial or complete, were observed on the nucleation surface following etching of the substrate. The only pin-holes that could be observed were those that had completely penetrated the coating. Over the whole area of impact, six completely penetrated pin-holes were seen on the nucleation surface. On the growth surface (i.e. the surface impacted by the sand particles), in addition to those six pin-holes, twelve partial or complete circumferential cracks and nine partially penetrated pin-holes were observed. The lower incidence of features on the nucleation surface therefore suggests that the circumferential cracks nucleate on the growth surface.

Figure 12 shows an electron micrograph of a pin-hole that had completely penetrated the coating viewed from the nucleation surface. It is interesting to note that the area surrounding the pin-hole appears to be free of tungsten. This corroborates the acoustic images and provides further evidence that circumferential cracks and pin-holes are formed on debonded areas of the coating. On the nucleation surface, all completely penetrated pin-holes were surrounded by a "halo" of tungsten-free diamond. The diameters of the pin-holes at the nucleation surface range from $160-330 \mu \mathrm{m}$, with the mean diameter being $228 \mu \mathrm{m}$. The tungsten-free regions surrounding these completely penetrated pin-holes ranged from $238 \mu \mathrm{m}$ to $675 \mu \mathrm{m}$, with the mean diameter being $450 \mu \mathrm{m}$. This also agrees well with the SAM images. Various scales of microstructural damage seen on both the nucleation and growth surfaces are summarised in Table 6.

\subsection{Mechanism of coating debonding}

If the circumferential cracks are formed by stress wave reflection and reinforcement at locally delaminated regions of the coating it is important to identify the mechanism by which the coating becomes delaminated. It is thought that the debonding process is assisted by the presence of grain-boundary porosity, which is present at the nucleation surface of the coating close to the interface. Such porosity may act as local stress raisers to provide nucleation sites for interfacial crack propagation. Other experiments have indicated that the coatings become delaminated under the action of sub-surface shear stresses that are generated during the particle impacts [18]. Rapid failure of the coating was observed when the maximum shear stresses were located at the coating-substrate interface (i.e. $z_{\tau} / C_{T}=1$ ). This work also indicated that for optimum coating performance $z_{\tau} / C_{T}$ should be less than 0.3 , in which case the stress field would be contained within the coating. In the present study, Table 4 shows that the tests of the 40 and $60 \mu \mathrm{m}$ coatings using the sieved 355-500 $\mu \mathrm{m}$ sand at a mean velocity of 
$268 \mathrm{~m} \mathrm{~s}^{-1}$ resulted in $z_{\tau} / C_{T}$ ratios of 0.69 and 0.46 respectively. It can be seen that the $z_{\tau} / C_{T}$ ratios of the coatings in Table 3 tested at 63,148 and $268 \mathrm{~m} \mathrm{~s}^{-1}$, which exhibited circumferential cracks and pin-holes, are below 0.3 , being between 0.13 and 0.26 . However, the values listed in the table are for the mean sand size $(194 \mu \mathrm{m})$ and the maximum shear stresses generated by the larger particles in the blend will be at significantly greater depths, thereby resulting in debonding of the coating and the formation of circumferential cracks and pin-holes. Therefore, circumferential cracks and pin-holes can provide a visible indication that coating delamination is taking place at the interface, which may result in catastrophic failure of the coating. The role of shear stresses in the generation of erosion damage to diamond coatings has been explored in detail in a separate publication [42].

Although Hertz appears to explain the generation of sub-surface damage in the coatings it should be noted that shear stresses have also been attributed to being the cause of sub-surface damage in non-Hertzian impact conditions, for example liquid impact, even though the assumption that the erodent and target are undeformed is plainly not the case. In studies of liquid impact on PMMA targets, Bowden and Brunton [43] found evidence of damage below the surface at a depth of approximately half the contact radius. This location is close to where the maximum shear stress occurs for elastic contact as predicted by Hertz. However, the shear stress is also likely to be augmented by the interaction of release waves from the contact periphery to give a net tension. This has been demonstrated experimentally in liquid impact studies of PMMA [44,45]. Jackson and Field [46] have also suggested that sub-surface damage could also be generated by the action of compressive or shear loading resulting in tensile failure at grain boundaries depending on the orientation and anisotropy of the adjacent grains. Therefore, in the present case there appear to be at least two competing stress fields (i.e. Hertzian and stress wave) created by the particle impacts, which together are responsible for the circumferential cracks and pin-holes.

In theoretical work, shear stress as a result of liquid impact has also been predicted $[47,48]$. In a finite element model of liquid impact onto a silicon sample coated with a $30 \mu \mathrm{m}$ diamond film, de Botton [48] found that the model predicted the existence of an intensive peak of inplane shear stresses just beneath the point at which the load terminates. However, further work is needed in order to obtain further insight into what is a complex issue and one in which much remains to be understood.

\subsection{Mechanism of crack propagation}

The stress wave reflection and reinforcement model has been shown to explain the formation of the circumferential cracks discussed in previous sections of this paper. However, the mechanism by which pin-holes are formed within these cracks is likely to be more complex and may be a combination of stress wave reinforcement and Hertzian stresses. Although the experimental evidence is limited, knowledge of impact-induced stress wave behaviour may be used to postulate a possible mechanism by which the pin-holes are formed.

Scanning electron microscopy of eroded coatings has shown that, following the formation of a circumferential crack, continued particle impacts cause these cracks to become more visible [19]. It is thought that the cracks are propagating through the coating in a direction approximately perpendicular to the surface. The driving force for this process is thought to be the Rayleigh surface waves, which account for $67 \%$ of the energy associated with impact [49]. The Rayleigh waves are tensile in nature and will open up these cracks causing them to propagate away from the growth surface towards the coating-substrate interface. In a liquid impact study of soda lime glass which had previously been subjected to indentation by a 
Vickers diamond pyramid, Swain and Hagan [50] found that the indentation-induced surface cracks increased in size following liquid impacts adjacent to these cracks. The cause of these observations was attributed to the Rayleigh waves, which are confined to the surface region of a material to a depth of approximately one wavelength. As a result of the high wave velocity in diamond, a depth of one wavelength is likely to be as much as $2 \mathrm{~mm}$, i.e. greater than the thickness of the coatings described in this paper. The figure of $2 \mathrm{~mm}$ was calculated assuming a frequency of $5 \mathrm{MHz}$, the inverse of the impact duration of $0.2 \mu \mathrm{sec}$ calculated using the Hertz equation (A6).

Figure 13 shows a micrograph of a circumferential crack in transverse section through the coating. The crack appears to take a trans-granular path through the coating. The crack can also be seen branching into two at a depth of approximately $15 \mu \mathrm{m}$ beneath the growth surface of the coating.

As the circumferential cracks penetrate deeper through the coating the central region inside the cracks becomes more compliant and susceptible to crack nucleation. Moreover, stress waves generated by impacts within the area bounded by the circumferential cracks may be reflected by the crack sides which may then reinforce other stress waves generated by adjacent impacts, the magnitude of which might be sufficient to cause the nucleation of cracks within the area bounded by the circumferential cracks. Furthermore, these stresses may be augmented by Hertzian tensile stresses at the surface and shear stresses below the surface. When a crack network has been established within the circumferential cracks, further particle impacts may result in the ejection of fragments of the coating, thereby creating a pin-hole, the depth of which subsequently increases with continuing particle impacts.

The sequence of damage accumulation caused by liquid impact has been described by van der Zwaag and Field [51] who subjected soda lime glass to repeated impacts of $0.8 \mathrm{~mm}$ diameter liquid droplets at $250 \mathrm{~m} \mathrm{~s}^{-1}$. The number and size of the surface cracks were found to increase with the number of impacts. After 23 impacts the cracking had intersected the rear surface creating a hole in the specimen. These observations partially mirror the present case when the coating is completely penetrated through to the coating-substrate interface.

In postulating this mechanism by which the pin-holes are formed it is recognised that more work is needed before it is possible to substantiate or refute this hypothesis. However, the task of achieving the former is not trivial and is beyond the scope of the present paper. Consequently, modelling of the process may provide greater understanding of the underlying mechanisms behind crack propagation through the coating and pin-hole formation.

\subsection{The nature of the erodent-target combination}

In studying the formation of impact damage generated by stress waves, it is necessary to consider the differences in elastic properties between particle and target. The difference in elastic constants between the two bodies can be quantified by the use of two independent variables, $\alpha$ and $\beta$ [52]. They can be calculated using the following expressions:

$$
\begin{gathered}
\alpha=\frac{\left\{\left(1-v_{1}\right) / G_{1}\right\}-\left\{\left(1-v_{2}\right) / G_{2}\right\}}{\left\{\left(1-v_{1}\right) / G_{1}\right\}+\left\{\left(1-v_{2}\right) / G_{2}\right\}} \\
\beta=\frac{1}{2}\left[\frac{\left\{\left(1-2 v_{1}\right) / G_{1}\right\}-\left\{\left(1-2 v_{2}\right) / G_{2}\right\}}{\left\{\left(1-v_{1}\right) / G_{1}\right\}+\left\{\left(1-v_{2}\right) / G_{2}\right\}}\right]
\end{gathered}
$$


$\alpha$ is a measure of the difference in plain strain modulus $\left\{\left(1-v^{2}\right) / E\right\}$ and has extreme values of -1.0 , when the target is rigid, and +1.0 , when the particle is rigid. $\beta$ varies between -0.5 and +0.5 , when one body is rigid and the other has zero Poisson's ratio. $\beta=0$ when both bodies are incompressible. The values of $\alpha$ and $\beta$ were calculated for the case of a silica sand particle impacting a diamond surface. The results are listed in Table 7 , together with three other combinations of particle and target. It can be seen that for both $\alpha$ and $\beta$ parameters, the combination of $\mathrm{SiO}_{2}$ and CVD diamond are close to the extreme values where the target is rigid and the particle highly deformable. It is interesting to compare the $\alpha$ and $\beta$ values for $\mathrm{SiO}_{2}$ and diamond with those for Nylon and PMMA. Impact studies using nylon spheres on PMMA targets showed circumferential cracking around the impact zone [6]. The values in Table 7 indicate that silica will show a greater propensity to deform when impacting on diamond than nylon does on PMMA. Therefore, on this basis, if stress wave induced damage can be generated on PMMA, similar behaviour should not be unexpected in the case of $\mathrm{SiO}_{2}$ impacting on diamond.

\section{Conclusions}

This paper has examined the damage features generated in diamond coatings by the impact of non-spherical silica sand particles at velocities of up to $268 \mathrm{~m} \mathrm{~s}^{-1}$. These features have been studied in detail in order to identify the mechanisms by which these features were formed.

No evidence of plastic deformation of the coatings was seen at the conditions employed during these tests. The low hardness and fracture toughness of the sand particles relative to diamond resulted in extensive fragmentation on impact with the diamond surfaces and prevented any elastic-plastic radial or lateral cracks in the coatings.

The diameters of the circumferential cracks do not agree with Hertz impact theory based on the mean sand size, with many cracks being between two and four times larger than the Hertzian contact diameters. Furthermore, a clear trend of increasing crack diameter with coating thickness, which is not predicted by Hertz, is observed over the range of coating thicknesses tested. This trend was also observed in tests using sieved sand with a significantly narrower size distribution.

Comparison of the measured circumferential crack diameters with the theory of stress wave reflection and reinforcement has shown good agreement between the former and the latter. This suggests that stress wave reflection and reinforcement at locally debonded regions of the coatings are responsible for the formation of the circumferential cracks observed on the diamond coatings tested as part of the present study. This hypothesis is supported by images acquired by scanning acoustic microscopy and electron micrographs of the nucleation surface of an eroded coating following dissolution of the tungsten substrate. They showed that the circumferential cracks and pin-holes were only found on regions where the coating had become debonded.

Scanning acoustic microscopy has been shown to be a valuable tool for the detection and examination of sub-surface damage in coatings. Its high spatial resolution has enabled individual circumferential cracks and pin-holes to be examined and has provided important evidence for identifying the mechanism responsible for the formation of circumferential cracks, the precursor to the pin-holes. 
The propagation of the circumferential cracks through the coating thickness and the nucleation and growth of the pin-holes within the circumferential cracks is likely to be a product of the interactions between Hertzian stresses (which are both tensile and shear) and the impact-induced stress waves. However, such interactions are complex and further modelling is necessary in order to understand such processes in more detail.

\section{Acknowledgements}

The authors wish to thank the EPSRC and De Beers Industrial Diamonds (UK) Ltd (now Element 6 Ltd.), for supporting the work and providing the specimens, and Alan Basterfield at Sonoscan (Europe) Ltd., for use of the scanning acoustic microscope.

\section{References}

1. P.W. May, Phil. Trans. R. Soc. Lond. A, 358, 473 (2000).

2. P. Hollman, H. Bjorkman, A. Alahelisten, S. Hogmark, Surf. Coat. Technol., 105, 169 (1998).

3. C.J.H. Wort, C.S.J. Pickles, A.C. Beale, C.G. Sweeney, M.R. McClymont, R.J. Saunders, R.S. Sussmann, K.L. Lewis, Proc. SPIE, 3705, 119 (1999).

4. D.W. Wheeler, R.J.K. Wood, D. Harrison, E. Smith, Wear, 261, 1087 (2006).

5. Z. Feng, Y. Tzeng, J.E. Field, Thin Solid Films, 212, 35 (1992).

6. R.H. Telling, G.H. Jilbert, J.E. Field, Proc. SPIE, 3060, 56 (1997).

7. R.H. Telling, J.E. Field, Wear, 233-235, 666 (1999).

8. S.P. Timoshenko, J.N. Goodier, Theory of Elasticity ( $3^{\text {rd }}$ ed.), McGraw-Hill, New York., (1970).

9. B.R. Lawn, J. Appl. Phys., 39, 4828 (1968).

10. D.W. Wheeler, R.J.K. Wood, Surf. Coat. Technol., 200, 4456 (2006).

11. D.W. Wheeler, R.J.K. Wood, Wear, 233-235, 306 (1999).

12. D.W. Wheeler, R.J.K. Wood, Diamond Relat. Mater., 10, 459 (2001).

13. D.W. Wheeler, R.J.K. Wood, Wear, 250, 795 (2001).

14. P.H. Shipway, I.M. Hutchings, Wear, 193, 105 (1996).

15. R.S. Sussmann, J.R. Brandon, G.A. Scarsbrook, C.G. Sweeney, T.J. Valentine, A.J. Whitehead, C.J.H. Wort, Diamond Relat. Mater., 3, 303 (1994).

16. R.J.K. Wood, D.W. Wheeler, Wear, 220, 95 (1998).

17. P.H. Shipway, I.M. Hutchings, Wear, 174, 169 (1994).

18. D.W. Wheeler, R.J.K. Wood, Surf. Eng., 19, 466 (2003).

19. D.W. Wheeler, R.J.K. Wood, in Proceedings of the International Tribology Conference, Nagasaki, Japan, 29 Oct - 2 Nov 2000, Japanese Society of Tribologists (2001), 1095.

20. D.W. Wheeler, R.J.K. Wood, Phil. Mag. Lett., 85, 367 (2005).

21. J.E. Field, E. Nicholson, C.R.Seward, Z. Feng, Phil. Trans. R. Soc. Lond. A, 342, 261 (1993).

22. C.S.J. Pickles, Diamond Relat. Mater., 11, 1913-1922 (2002).

23. S.C. Hunter, J. Mech. Phys. Solids, 5, 162 (1957).

24. D.W. Wheeler, PhD Thesis, University of Southampton (2001).

25. K.L. Johnson, J.J. O'Connor, A.C.Woodward, Proc. R. Soc. Lond. A, 334, 95 (1973).

26. J.E. Field, Q.Sun, H. Gao, Proc. SPIE, 2286, 301 (1994).

27. E. Lassner, W.D. Schubert, Tungsten, Kluwer Academic / Plenum Publishers, New York (1999).

28. S.G. Roberts, C.W. Lawrence, Y. Bisrat, P.D. Warren, D.A. Hills, J. Am. Ceram. Soc., 82, 1809 (1999).

29. S.G. Roberts, Brit. Ceram. Trans., 99, 31 (2000).

30. F.P. Bowden, J.E. Field, Proc. R. Soc. Lond. A, 282, 331 (1964). 
31. E.J. Coad, J.E. Field, Proc. SPIE, 3060, 169 (1997).

32. C.R.Seward, J.E. Field, E.J. Coad, J. Hard Mater., 5, 49 (1994).

33. J.E. Field, The Properties of Natural and Synthetic Diamond, Academic Press (1992).

34. M.J. Jackson, J.E. Field, Wear, 233-235, 39 (1999).

35. Y.Y. Yang, Y.S. Jin, S.Y. Luo, Surf. Coat. Technol., 91, 95 (1997).

36. C. Delebarre, C. Bruneel, R. Delwiche, I. De Vos, NDT \& E Int., 26, 303 (1993).

37. H. Peng, S. Hu, Y. Jin, in Proceedings of the International Tribology Conference, Nagasaki, Japan, 29 Oct - 2 Nov 2000, Japanese Society of Tribologists (2001), 949.

38. C. Bellan, J. Dhers, Thin Solid Films, 469-470, 214 (2004).

39. P.D. Warren, C. Pecorari, O.V. Kolosov, S.G. Roberts, G.A.D. Briggs, Nanotechnology, 7, 295 (1996).

40. C. Pecorari, C.W. Lawrence, S.G. Roberts, G.A.D. Briggs, Phil. Mag. A., 80, 2695 (2000).

41. D.W. Wheeler, R.J.K. Wood, Wear, 225-229, 523 (1999).

42. D.W. Wheeler, R.J.K. Wood, Phil. Mag., 87, 5719 (2007).

43. F.P. Bowden, J.H. Brunton, Proc. R. Soc. Lond. A, 263, 433 (1961).

44. T. Obara, N.K. Bourne, J.E. Field, Wear, 186-187, 388 (1995).

45. N.K. Bourne, T. Obara, J.E. Field, Phil. Trans. R. Soc. Lond. A, 355, 607 (1997).

46. M.J. Jackson, J.E. Field, Phil. Mag. Lett., 80, 27 (2000).

47. G. de Botton, Comput. Modeling Simulation Eng., 2, 177 (1997).

48. G. de Botton, Wear, 219, 60 (1998).

49. G.F. Miller, H. Pursey, Proc. R. Soc. Lond. A, 233, 55 (1955).

50. M.V. Swain, J.T. Hagan, J. Mater. Sci., 15, 387 (1980).

51. S. van der Zwaag, J.E. Field, Eng. Fract. Mech., 17, 367 (1983).

52. K.L. Johnson, Contact Mechanics, Cambridge University Press (1985). 


\section{LIST OF TABLES}

Table 1: Relevant physical properties of diamond and sand.

Table 2: Results from erosion tests of CVD diamond coatings comparing the measured circumferential crack diameters with the Hertzian contact diameters at velocities of between 63 and $268 \mathrm{~m} \mathrm{~s}^{-1}$.

Table 3: Contact conditions generated by the impact of 63-600 $\mu \mathrm{m}$ sand (average diameter $194 \mu \mathrm{m})$ at velocities of between 33 and $268 \mathrm{~m} \mathrm{~s}^{-1}$ on diamond coatings $39-46 \mu \mathrm{m}$ in thickness, calculated using Hertzian impact theory.

Table 4: Contact conditions generated by the impact of 355-500 $\mu \mathrm{m}$ sand (average diameter $442 \mu \mathrm{m}$ ) at a velocity of $268 \mathrm{~m} \mathrm{~s}^{-1}$ on 40 and $60 \mu \mathrm{m}$ diamond coatings, calculated using Hertzian impact theory.

Table 5: Measured circumferential crack diameters as a function of coating thickness $\left(C_{T}\right)$ for CVD diamond coatings eroded by $63-600 \mu \mathrm{m}$ sand at $268 \mathrm{~m} \mathrm{~s}^{-1}$ and compared with the predicted stress wave (SW) reinforcement diameter.

Table 6: Summary of erosion damage features as measured from an eroded $60 \mu \mathrm{m}$ coating using scanning acoustic microscope images (SAM) and scanning electron micrographs (SEM) of free-standing coatings following removal of the substrate.

Table 7: Values of $\alpha$ and $\beta$ parameters for a number of particle and target combinations. 


\section{LIST OF FIGURES}

Fig. 1: Scanning electron micrograph of an untested diamond coating.

Fig. 2: Graph of cumulative mass loss (CML) vs. time for the erosion of a $46 \mu \mathrm{m}$ lapped diamond coating tested at a particle velocity of $268 \mathrm{~m} \mathrm{~s}^{-1}$ showing the three stages of erosion.

Fig. 3: Scanning electron micrograph of a circumferential crack on an eroded diamond coating.

Fig. 4: Scanning electron micrograph of a circumferential crack and pin-hole on an eroded diamond coating.

Fig. 5: Graph showing the relationship between circumferential crack diameter and particle velocity for CVD diamond coatings.

Fig. 6: Two possible processes of stress wave reinforcement to generate circumferential cracks in CVD diamond.

Fig. 7: Graph of measured average circumferential crack diameter vs. coating thickness for CVD diamond coatings on tungsten, which were erosion tested at $268 \mathrm{~m} \mathrm{~s}^{-1}$.

Fig. 8: SAM image of an untested $60 \mu \mathrm{m}$ diamond coating on tungsten.

Fig. 9: SAM image of a $60 \mu \mathrm{m}$ diamond coating, tested for 5 hours at $268 \mathrm{~m} \mathrm{~s}^{-1}$, showing delamination (white areas) and a pin-hole (circular purple feature in the centre of the image) located on a delaminated region of the coating.

Fig. 10: Micrograph of the nucleation surface of a $60 \mu \mathrm{m}$ diamond coating, tested at $268 \mathrm{~m} \mathrm{~s}^{-1}$ for 5 hours following dissolution of the tungsten substrate.

Fig. 11: Micrograph of the nucleation surface of the same sample as Figure 10, showing cracks propagating away from a tungsten-free area, which was thought to have been a delaminated region of the coating prior to dissolution of the substrate.

Fig. 12: Micrograph of the nucleation surface of a $60 \mu \mathrm{m}$ diamond coating, tested at $268 \mathrm{~m} \mathrm{~s}^{-1}$ for 5 hours showing a pin-hole that has completely penetrated the coating surrounded by tungsten-free diamond.

Fig. 13: Micrograph of a transverse section of the $60 \mu \mathrm{m}$ coating shown in Figures 10 to 12 showing a circumferential crack (arrowed) extending through the coating in the direction of the coating-substrate interface. 


\begin{tabular}{|l|c|c|}
\hline Property & CVD Diamond & Silica sand $\left(\mathrm{SiO}_{2}\right)$ \\
\hline Elastic modulus $(\mathrm{GPa})$ & 1157 & 87 \\
\hline Poisson's ratio & 0.07 & 0.21 \\
\hline Density $\left(\mathrm{kg} \mathrm{m}^{-3}\right)$ & 3520 & 2650 \\
\hline Hardness $(\mathrm{GPa})$ & 80 & 13.1 \\
\hline Fracture Toughness $(\mathrm{MPa} \sqrt{\mathrm{m}})$ & 6.0 & 1.4 \\
\hline
\end{tabular}

Table 1: Relevant physical properties of diamond and sand. The data for the silica sand are taken from Telling and Field [7] and Shipway and Hutchings [14] while the data for diamond are taken from Sussmann et al [15]. 


\begin{tabular}{|c|c|c|c|c|c|}
\hline $\begin{array}{c}\text { Velocity } \\
\left(\mathrm{m} \mathrm{s}^{-1}\right)\end{array}$ & $\begin{array}{c}\text { Coating } \\
\text { thickness } \\
(\mu \mathrm{m})\end{array}$ & $\begin{array}{c}\text { Hertzian } \\
\text { contact } \\
\text { diameter } \\
(\mu \mathrm{m})\end{array}$ & $\begin{array}{c}\text { Mean crack } \\
\text { diameter }(\mu \mathrm{m})\end{array}$ & $\begin{array}{c}\text { Range of } \\
\text { crack } \\
\text { diameters } \\
(\mu \mathrm{m})\end{array}$ & $\begin{array}{c}\text { Standard } \\
\text { deviation }\end{array}$ \\
\hline 33 & 40 & 34 & $\begin{array}{c}\text { No cracks } \\
\text { observed }\end{array}$ & N/A & N/A \\
63 & 39 & 46 & 170 & $130-200$ & 20 \\
148 & 46 & 64 & 182 & $150-250$ & 27 \\
268 & 46 & 82 & 193 & $150-245$ & 30 \\
\hline 148 & 60 & 64 & 244 & $175-340$ & 48 \\
189 & 60 & 70 & 234 & $200-295$ & 39 \\
232 & 60 & 76 & 300 & $255-365$ & 39 \\
268 & 60 & 82 & 281 & $250-313$ & 20 \\
\hline
\end{tabular}

Table 2: Results from erosion tests of CVD diamond coatings comparing the measured circumferential crack diameters with the Hertzian contact diameters at velocities of between 63 and $268 \mathrm{~m} \mathrm{~s}^{-1}$. 


\begin{tabular}{|l|c|c|c|c|}
\hline Velocity $V\left(\mathrm{~m} \mathrm{~s}^{-1}\right)$ & 33 & 63 & 148 & 268 \\
\hline Mean particle radius $R(\mu \mathrm{m})$ & 97 & 97 & 97 & 97 \\
\hline Coating thickness, $C_{T}(\mu \mathrm{m})$ & 40 & 39 & 46 & 46 \\
\hline Range of particle radii $(\mu \mathrm{m})$ & $32-300$ & $32-300$ & $32-300$ & $32-300$ \\
\hline Mean $E_{k}(\mu \mathrm{J})$ & 5.6 & 20 & 110 & 366 \\
\hline Maximum contact load $F_{m}(\mathrm{~N})$ & 4.4 & 10 & 27 & 54 \\
\hline Max contact pressure $P_{o}(\mathrm{GPa})$ & 6.9 & 8.9 & 12.5 & 15.9 \\
\hline Mean contact pressure $P_{m}(\mathrm{GPa})$ & 4.6 & 5.9 & 8.3 & 10.6 \\
\hline Mean contact radius $a_{m}(\mu \mathrm{m})$ & 17 & 23 & 32 & 38 \\
\hline $\begin{array}{l}\text { Mean measured circumferential } \\
\text { crack diameter }(\mu \mathrm{m})\end{array}$ & - & 170 & 182 & 193 \\
\hline Tensile stress $\sigma_{m}(\mathrm{GPa})$ & 2.0 & 2.5 & 3.6 & 4.6 \\
\hline Time of impact, $t_{e}(\mu \mathrm{s})$ & 0.28 & 0.25 & 0.21 & 0.19 \\
\hline Maximum shear stress $\tau_{m}(\mathrm{GPa})$ & 2.1 & 2.7 & 3.9 & 4.9 \\
\hline $\begin{array}{l}\text { Depth of maximum shear stress, } z_{\tau} \\
(\mu \mathrm{m})\end{array}$ & 5.4 & 7.4 & 10.2 & 12.2 \\
\hline$z_{\tau} / C_{T}$ & 0.14 & 0.19 & 0.22 & 0.27 \\
\hline$C_{T} / a_{m}$ & 2.36 & 1.7 & 1.46 & 1.12 \\
\hline Number of impacts on area $A\left(\mathrm{hr}{ }^{-1}\right)$ & 653 & 1196 & 2316 & 3802 \\
\hline $\begin{array}{l}\text { Time required to form } 1^{\text {st }} \\
\text { circumferential crack }(\mathrm{hrs})\end{array}$ & $\begin{array}{c}\text { No cracks } \\
\text { observed }\end{array}$ & 12.0 & 3.0 & 1.0 \\
\hline $\begin{array}{l}\text { No. of impacts to form } 1^{\text {st }} \\
\text { circumferential crack } N(H e r t z)\end{array}$ & $\begin{array}{c}\text { No cracks } \\
\text { observed }\end{array}$ & 14362 & 6948 & 3802 \\
\hline
\end{tabular}

Table 3: Contact conditions generated by the impact of $63-600 \mu \mathrm{m}$ sand (average diameter $194 \mu \mathrm{m}$ ) at velocities of between 33 and $268 \mathrm{~m} \mathrm{~s}^{-1}$ on diamond coatings 39$46 \mu \mathrm{m}$ in thickness, calculated using Hertzian impact theory. 


\begin{tabular}{|c|c|c|}
\hline Coating thickness, $C_{T}(\mu \mathrm{m})$ & 40 & 60 \\
\hline Velocity $V\left(\mathrm{~m} \mathrm{~s}^{-1}\right)$ & 268 & 268 \\
\hline Range of particle velocities $\left(\mathrm{m} \mathrm{s}^{-1}\right)$ & $253-298$ & $253-298$ \\
\hline Mean particle radius $R(\mu \mathrm{m})$ & 221 & 221 \\
\hline Range of particle radii $(\mu \mathrm{m})$ & $178-250$ & $178-250$ \\
\hline Mean $E_{k}(\mu \mathrm{J})$ & 3907 & 3907 \\
\hline Maximum contact load $F_{m}(\mathrm{~N})$ & 302 & 302 \\
\hline Max contact pressure $P_{o}(\mathrm{GPa})$ & 20.9 & 20.9 \\
\hline Mean contact pressure $P_{m}(\mathrm{GPa})$ & 13.9 & 13.9 \\
\hline Mean contact radius $a_{m}(\mu \mathrm{m})$ & 83 & 83 \\
\hline Range of contact radii $(\mu \mathrm{m})$ & $136-204$ & $136-204$ \\
\hline Mean measured circumferential crack diameter $(\mu \mathrm{m})$ & 178 & 269 \\
\hline Range of circumferential crack diameters $(\mu \mathrm{m})$ & $130-220$ & $249-300$ \\
\hline Tensile stress $\sigma_{m}(\mathrm{GPa})$ & 6.0 & 6.0 \\
\hline Time of impact, $t_{e}(\mu \mathrm{s})$ & 0.35 & 0.35 \\
\hline Maximum shear stress $\tau_{m}(\mathrm{GPa})$ & 6.5 & 6.5 \\
\hline Depth of maximum shear stress, $z_{\tau}(\mu \mathrm{m})$ & 27 & 27 \\
\hline 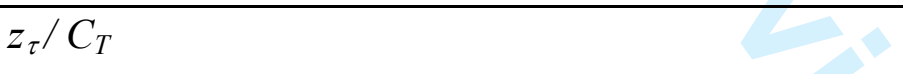 & 0.68 & 0.45 \\
\hline$C_{T} / a_{m}$ & 0.48 & 0.72 \\
\hline Number of impacts on area $A\left(\mathrm{hr}^{-1}\right)$ & 1321 & 1321 \\
\hline Time required to form $1^{\text {st }}$ circumferential crack (hrs) & 0.75 & 3.0 \\
\hline $\begin{array}{l}\text { No. of impacts to form } 1^{\text {st }} \text { circumferential crack } N \\
\text { (Hertz) }\end{array}$ & 991 & 3963 \\
\hline
\end{tabular}

Table 4: Contact conditions generated by the impact of $355-500 \mu \mathrm{m}$ sand (average diameter $442 \mu \mathrm{m}$ ) at a velocity of $268 \mathrm{~m} \mathrm{~s}^{-1}$ on 40 and $60 \mu \mathrm{m}$ diamond coatings, calculated using Hertzian impact theory. 


\begin{tabular}{|c|c|c|c|c|c|}
\hline$C_{T}(\mu \mathrm{m})$ & $\begin{array}{c}\text { Grain size } \\
(\mu \mathrm{m})\end{array}$ & $\begin{array}{c}\text { Mean crack } \\
\text { diameter } \\
(\mu \mathrm{m})\end{array}$ & $\begin{array}{c}\text { Range of crack } \\
\text { diameters }(\mu \mathrm{m})\end{array}$ & $\begin{array}{c}\text { Stress wave } \\
\text { reinforcement } \\
\text { diameter }\left(d_{1}\right) \\
(\mu \mathrm{m})\end{array}$ & $\begin{array}{c}\text { Stress wave } \\
\text { reinforcement } \\
\text { diameter }\left(d^{\prime}\right) \\
(\mu \mathrm{m})\end{array}$ \\
\hline 33 & $12-30$ & 163 & $110-225$ & 109 & 150 \\
\hline $40 \#$ & $20-40$ & 178 & $130-220$ & 142 & 192 \\
\hline 46 & $20-40$ & 193 & $150-245$ & 149 & 206 \\
\hline 60 & $30-60$ & 281 & $250-313$ & 191 & 266 \\
\hline $60 \#$ & $30-60$ & 269 & $249-300$ & 202 & 277 \\
\hline 90 & $18-40$ & 387 & $-*$ & 283 & 394 \\
\hline
\end{tabular}

Table 5: Measured circumferential crack diameters as a function of coating thickness $\left(C_{T}\right)$ for CVD diamond coatings eroded by $63-600 \mu \mathrm{m}$ sand at $268 \mathrm{~m} \mathrm{~s}^{-1}$ and compared with the predicted stress wave (SW) reinforcement diameter.

Key: \# = coating eroded by sieved $355-500 \mu \mathrm{m}$ sand; * = not applicable as only one circumferential crack was seen on that specimen. 


\begin{tabular}{|l|c|c|}
\hline Damage feature & $\begin{array}{c}\text { Size of features measured } \\
\text { by SAM }(\mu \mathrm{m})\end{array}$ & $\begin{array}{c}\text { Size of features measured } \\
\text { by SEM }(\mu \mathrm{m})\end{array}$ \\
\hline Interfacial delamination & $\begin{array}{c}271(\text { mean }) \\
75-634(\text { range })\end{array}$ & $\begin{array}{c}238(\text { mean }) \\
7-675(\text { range) }\end{array}$ \\
\hline $\begin{array}{l}\text { Distance between } \\
\text { delaminated regions }\end{array}$ & $\begin{array}{c}364 \text { (mean) } \\
84-890 \text { (range) }\end{array}$ & $42-110$ (range) \\
\hline Diameter of pin-holes* & 182 (mean) & 187 (mean) \\
& $91-273$ (range) & $130-330$ (range) \\
\hline
\end{tabular}

Table 6: Summary of erosion damage features as measured from an eroded $60 \mu \mathrm{m}$ coating using scanning acoustic microscope images (SAM) and scanning electron micrographs (SEM) of free-standing coatings following removal of the substrate. N.B. $*=$ the diameter of the central region within the circumferential crack from which fragments of the coating have been ejected. 


\begin{tabular}{|c|c|c|c|c|c|c|c|}
\hline Body 1 (Target) & $\begin{array}{c}\text { Body 2 } \\
(\text { Particle) }\end{array}$ & $G_{1}(\mathrm{GPa})$ & $v_{1}$ & $G_{2}(\mathrm{GPa})$ & $v_{2}$ & $\alpha$ & $\beta$ \\
\hline CVD diamond & $\mathrm{SiO}_{2}$ & 541 & 0.07 & 36 & 0.21 & -0.85 & -0.31 \\
\hline PMMA & Nylon & 1.40 & 0.38 & 0.25 & 0.38 & -0.62 & -0.21 \\
\hline Glass & Steel & 22 & 0.25 & 80 & 0.31 & 0.57 & 0.21 \\
\hline Tungsten carbide & Steel & 300 & 0.22 & 80 & 0.30 & -0.54 & -0.24 \\
\hline
\end{tabular}

Table 7: Values of $\alpha$ and $\beta$ parameters for a number of particle and target combinations. 


\section{Appendix: The use of Hertz impact theory to calculate contact conditions}

The procedure for calculating the contact conditions for the case of a particle impacting the surface of a target according to Hertz theory is given below [A1]. The maximum load, $F_{m}$, is calculated using:

$$
F_{m}=\left(\frac{5 \pi \rho_{e}}{3}\right)^{3 / 5}\left(\frac{4 k}{3 E_{1}}\right)^{-2 / 5} R^{2} V^{6 / 5}
$$

The mean contact pressure, $P_{m}$, is:

$$
P_{m}=\frac{1}{\pi}\left(\frac{5 \pi \rho_{e}}{3}\right)^{1 / 5}\left(\frac{4 k}{3 E_{1}}\right)^{-4 / 5} V^{2 / 5}
$$

where $\rho_{e}$ is the density of the impacting particle, $E_{1}$ the elastic modulus of the diamond, $R$ the particle radius and $V$ the particle velocity. The value of $k$ is obtained using the following equation:

$$
k=\frac{9}{16}\left[\left(1-v_{1}^{2}\right)+\left\{\left(1-v_{2}^{2}\right)\left(\frac{E_{1}}{E_{2}}\right)\right\}\right]
$$

where $E_{1}, v_{1}$ and $E_{2}, v_{2}$ are the elastic modulae and Poisson's ratios of the target material and erodent respectively. The values of $F_{m}$ and $P_{m}$, from Equations (A1) to (A3), can be used to calculate the maximum contact radius, $a_{m}$ :

$$
a_{m}=\sqrt{\frac{F_{m}}{\pi P_{m}}}
$$

The maximum tensile stress at the contact circle, $\sigma_{m}$, can also be calculated, using the following formula:

$$
\sigma_{m}=\frac{1}{2}\left(1-2 v_{1}\right) P_{m}
$$

The expression used to calculate the duration of elastic impact, $t_{e}$, can be calculated using the following formula:

$$
t_{e}=2.94\left[\frac{5 \pi \rho}{4}\left(\frac{1-v_{1}^{2}}{E_{1}}+\frac{1-v_{2}^{2}}{\mathrm{E}_{2}}\right)\right]^{2 / 5} V^{-1 / 5} R
$$

For a circular point contact, a shear stress is generated in the region beneath the contact zone. The maximum value of this shear stress, $\tau_{m}$, can be calculated, assuming no relative motion at the interface, using: 


$$
\tau_{m}=0.31\left(\frac{3 P_{m}}{2}\right)
$$

The depth, $z_{\tau}$, at which this occurs, is:

$$
z_{\tau}=0.32 a_{m}
$$

The depth given in the equation above, $z_{\tau}=0.32 a_{m}$ is lower than the usually quoted figure of $0.48 a_{m}$. However, this latter figure is for materials having a Poisson's ratio of 0.3 . The considerably lower Poisson's ratio of diamond (0.07) has necessitated recalculation [A2], hence the revised figure.

The number of particle impacts per Hertzian zone $N($ Hertz) is calculated using the following expression:

$$
N(\text { Hertz })=\frac{A F t}{m_{s}}
$$

Where $F$ is the flux rate in $\mathrm{kg} \mathrm{m}^{-2} \mathrm{~s}^{-1}, t$ is the test duration and $m_{e}$ is the mass of the erodent particle, given by $\left(4 \rho_{e} \pi R^{3}\right) / 3 . A$ is the size of the Hertzian zone, which is defined as:

$$
A=\pi\left(2 a_{m}\right)^{2}
$$

This calculation assumes that any impact having its centre within $2 a_{m}$ will overlap the previous one.

\section{Reference}

A1. S.P. Timoshenko, J.N. Goodier, Theory of Elasticity ( $3^{\text {rd }}$ ed.), McGraw-Hill, New York (1970).

A2. D.W. Wheeler, R.J.K. Wood, Phil. Mag., 87, 5719 (2007). 


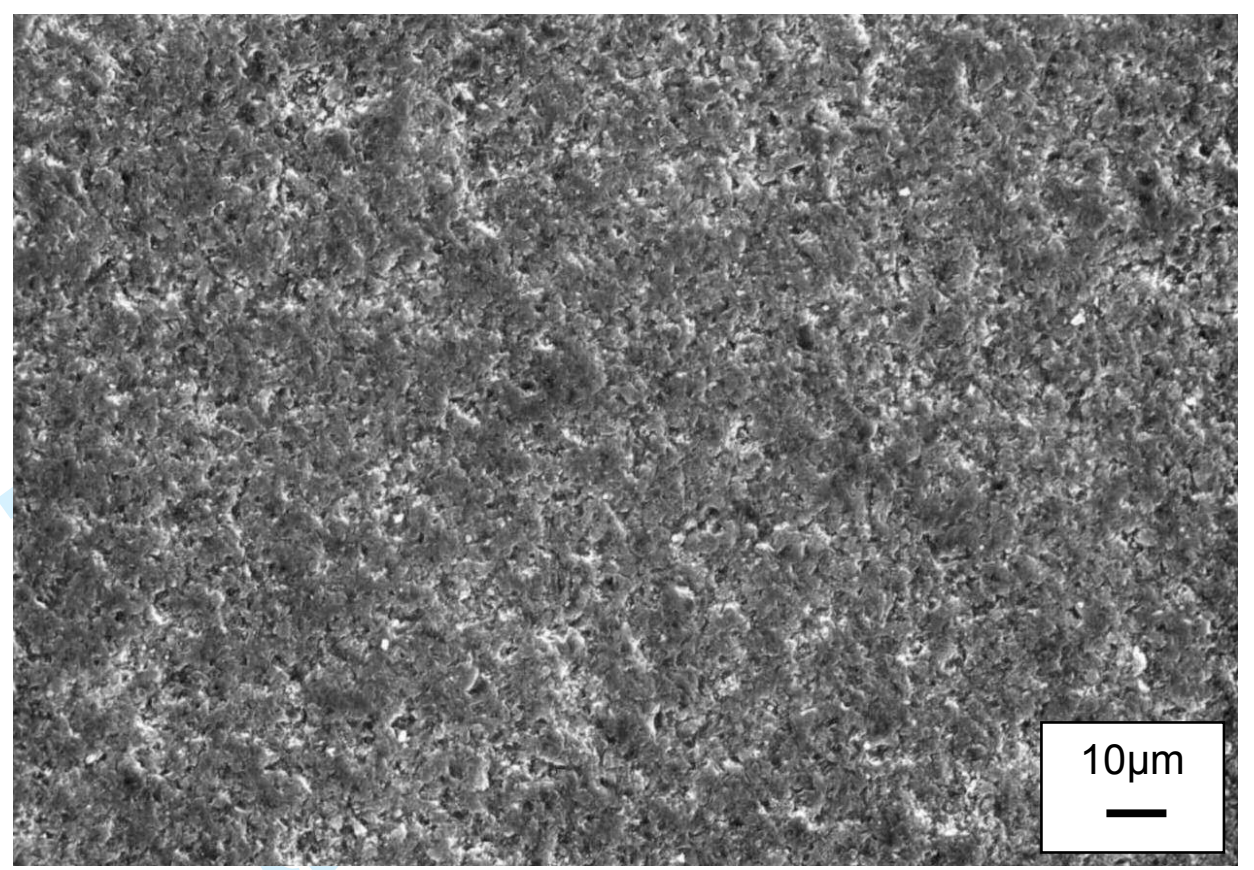

Fig. 1: Scanning electron micrograph of an untested diamond coating. 


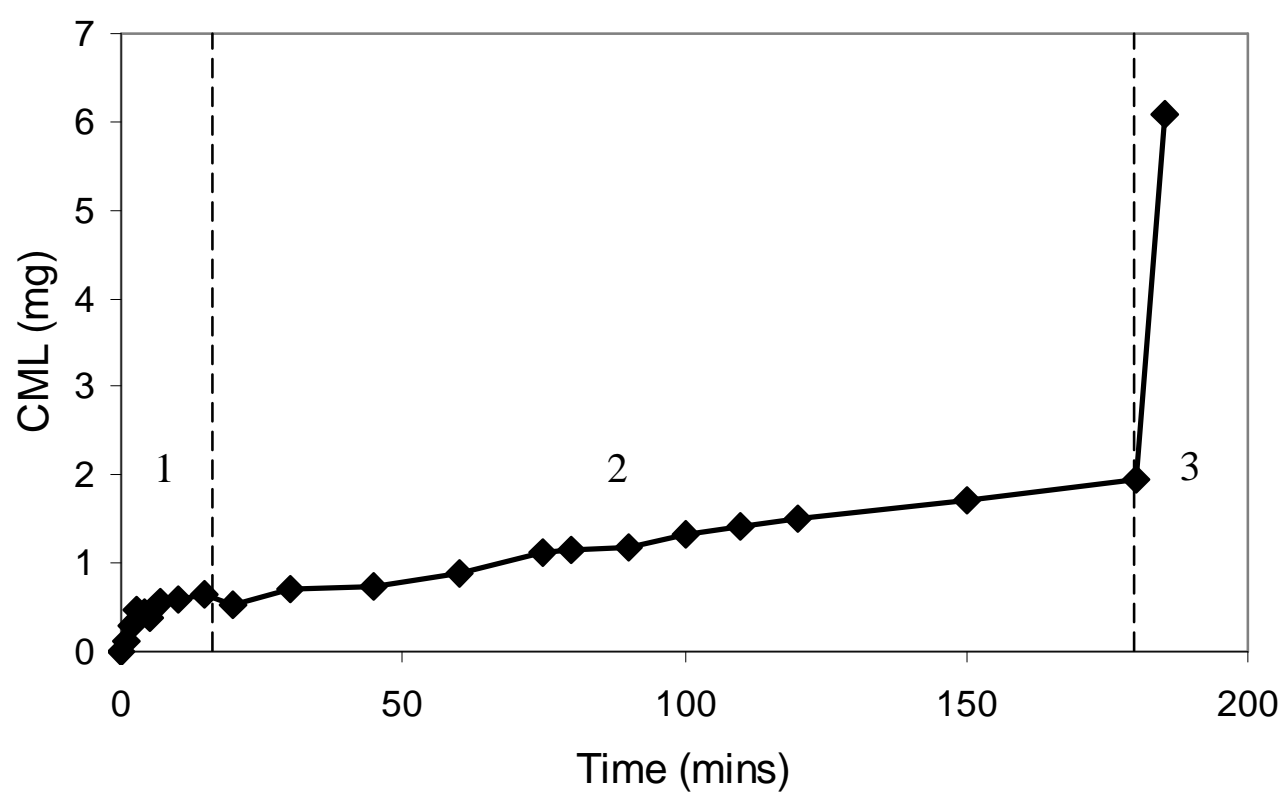

Fig. 2: Graph of cumulative mass loss (CML) vs. time for the erosion of a $46 \mu \mathrm{m}$ lapped diamond coating tested at a particle velocity of $268 \mathrm{~m} \mathrm{~s}^{-1}$ showing the three stages of erosion: (1) initial incubation period; (2) steady state erosion, the gradient of which denotes the erosion rate; (3) catastrophic failure of the coating. 


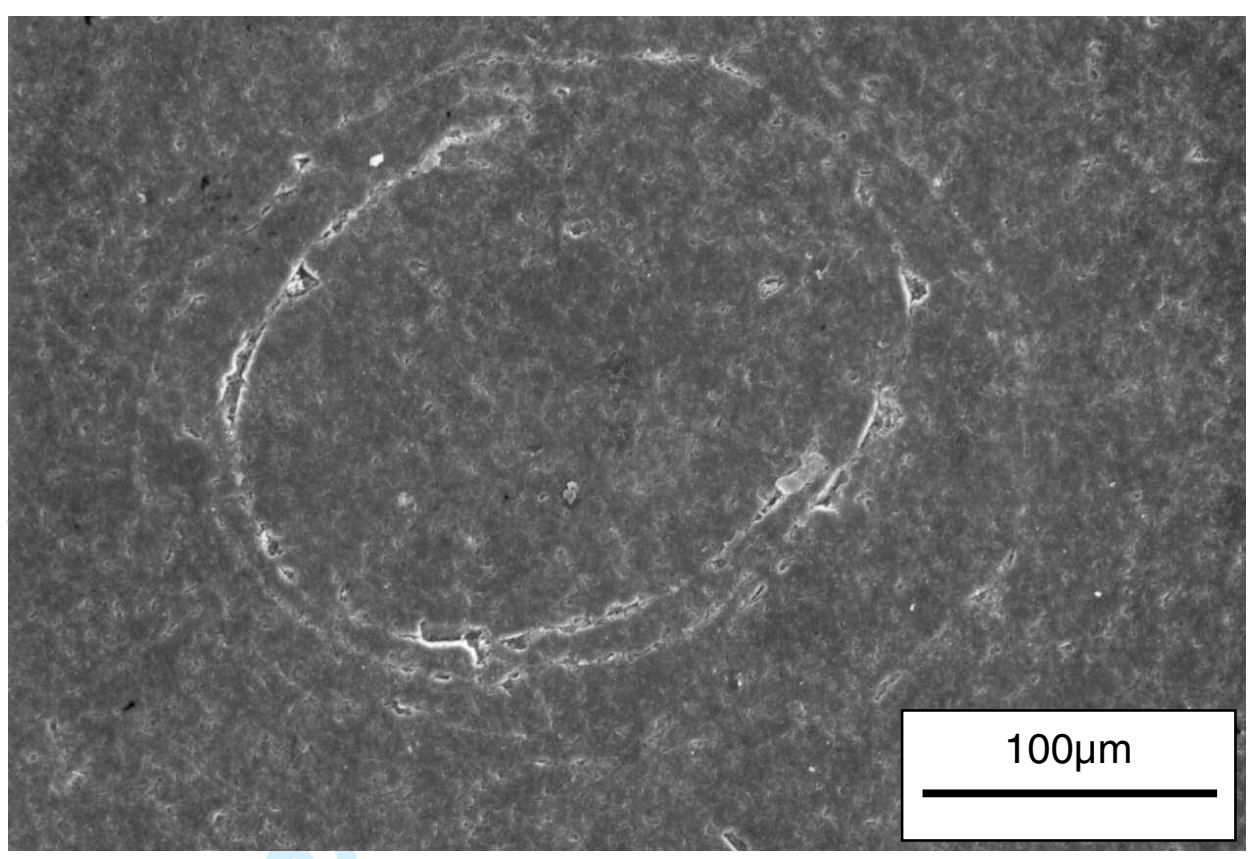

Fig. 3: Scanning electron micrograph of a circumferential crack on an eroded diamond coating. 


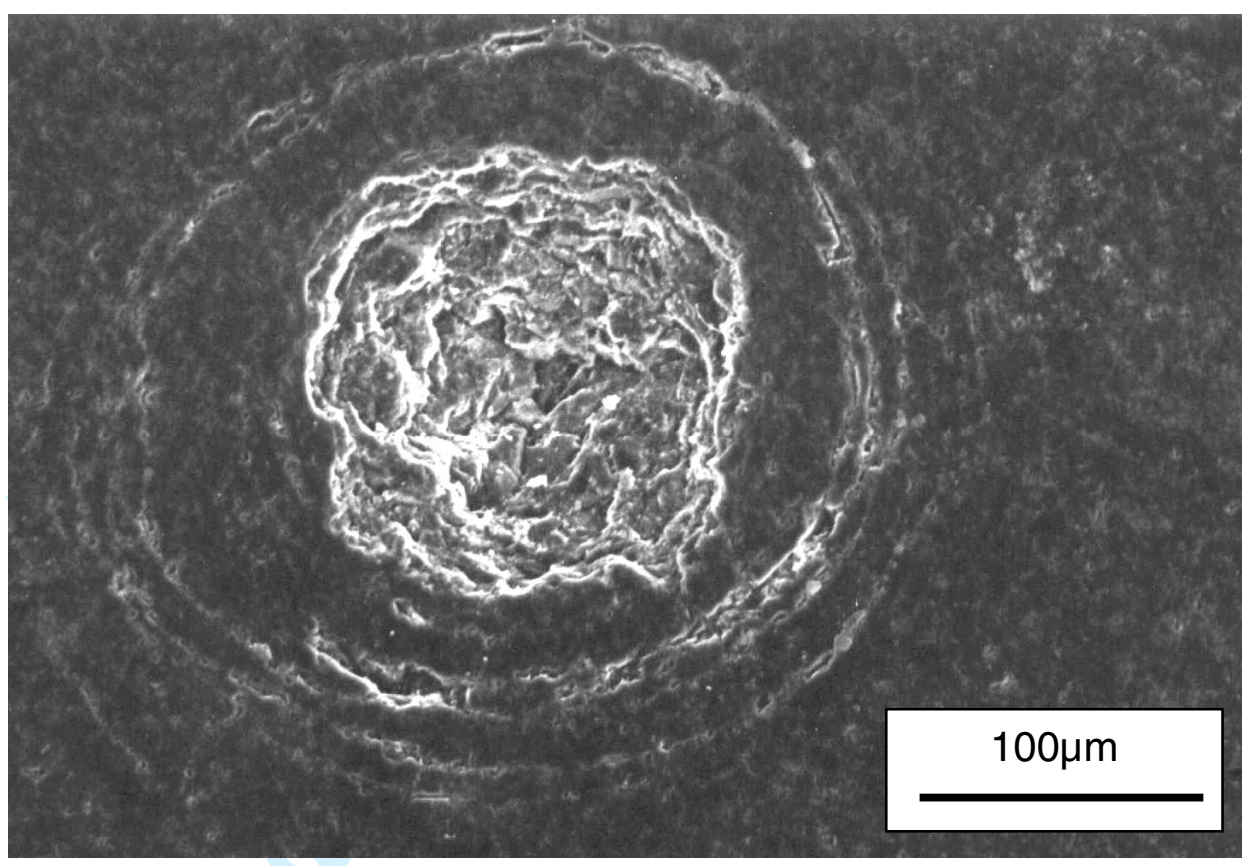

Fig. 4: Scanning electron micrograph of a circumferential crack and pin-hole on an eroded diamond coating. 


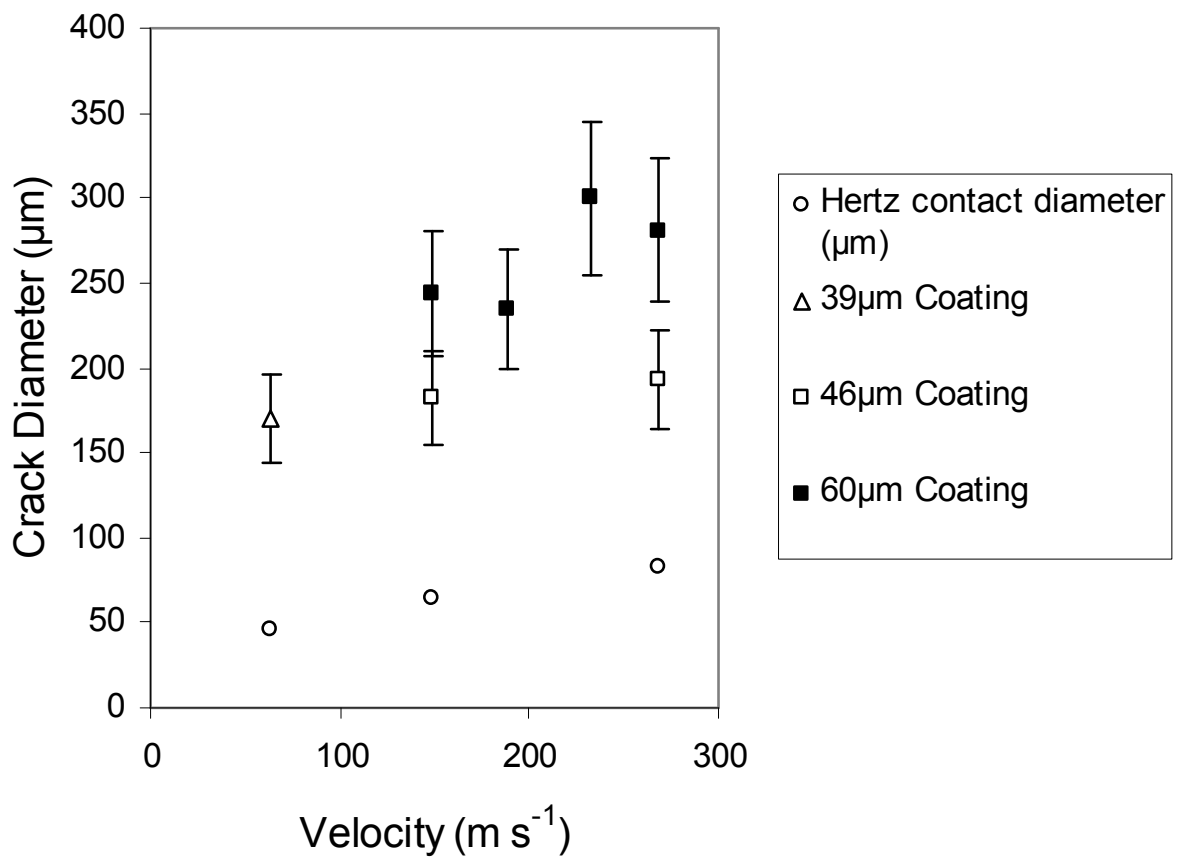

Fig. 5: Graph showing the relationship between circumferential crack diameter and particle velocity for CVD diamond coatings. The Hertzian contact diameter is also included for comparison. 

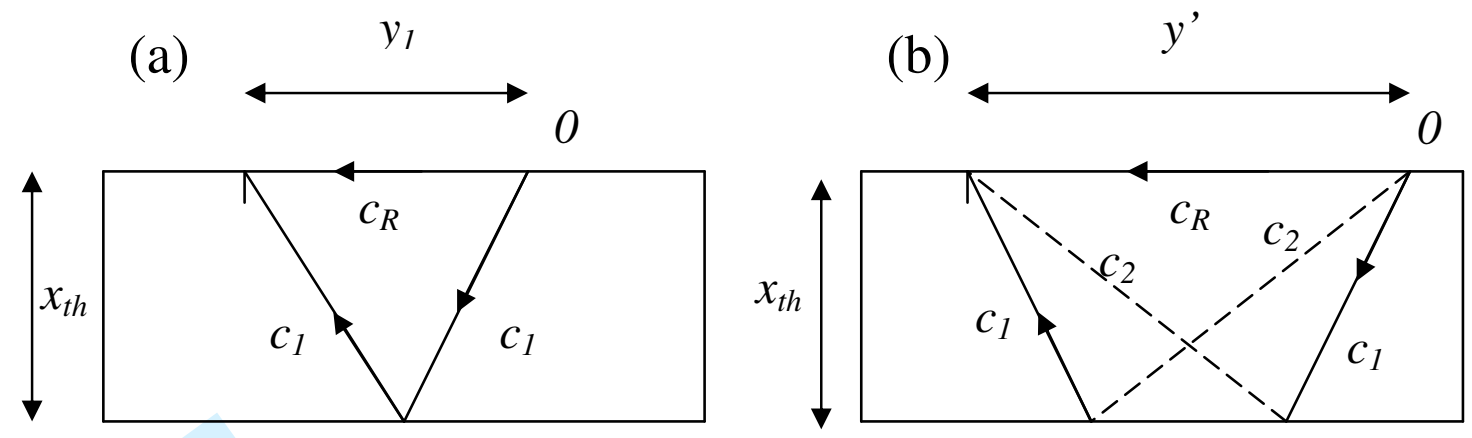

Fig. 6: Two possible processes of stress wave reinforcement to generate circumferential cracks in CVD diamond [29]. Key: $c_{1}=$ compression wave; $c_{2}=$ shear wave; $c_{R}=$ Rayleigh wave; $0=$ Origin of impact. The thickness, $x_{\text {th }}$, has been replaced by $\mathrm{C}_{\mathrm{T}}$, the coating thickness in the present work. 


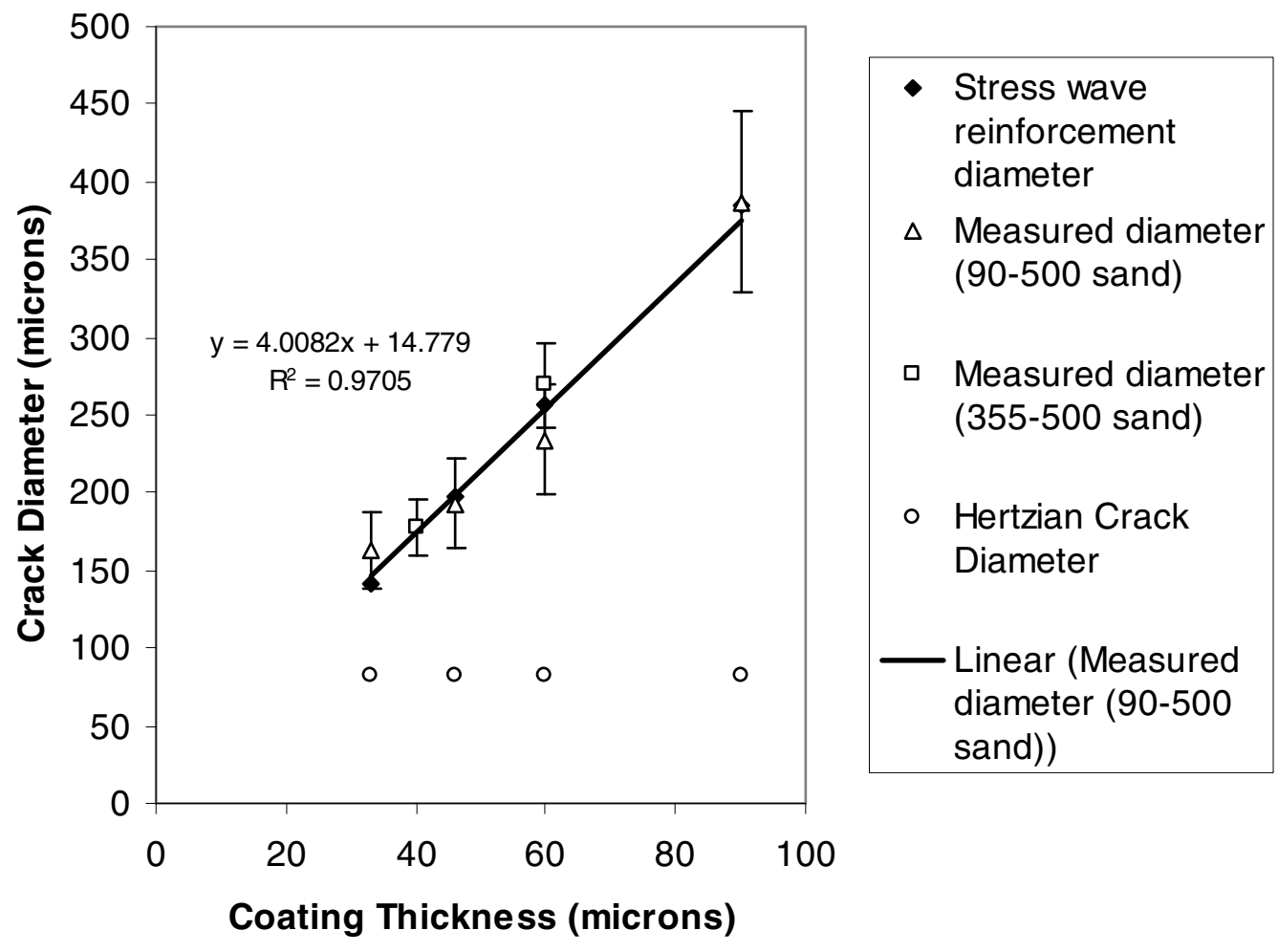

Fig. 7: Graph of measured average circumferential crack diameter vs. coating thickness for CVD diamond coatings on tungsten, which were erosion tested at $268 \mathrm{~m}$ $\mathrm{s}^{-1}$. The calculated stress wave reinforcement diameter and Hertzian contact diameter have also been included for comparison. 
Fig. 8: SAM image of an untested $60 \mu \mathrm{m}$ diamond coating on tungsten. 


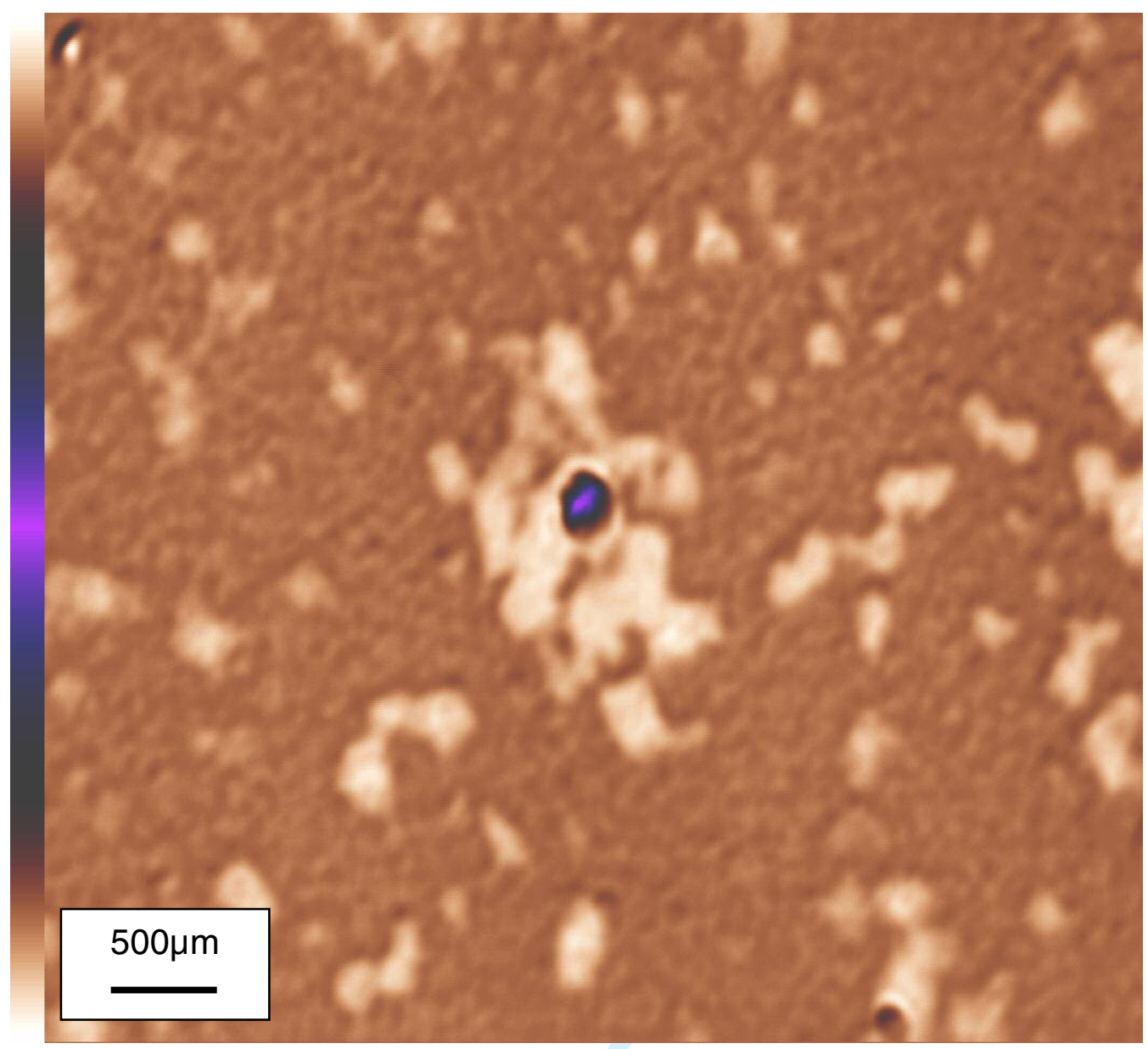

Fig. 9: SAM image of a $60 \mu \mathrm{m}$ diamond coating, tested for 5 hours at $268 \mathrm{~m} \mathrm{~s}^{-1}$, showing delamination (white areas) and a pin-hole (circular purple feature in the centre of the image) located on a delaminated region of the coating. 


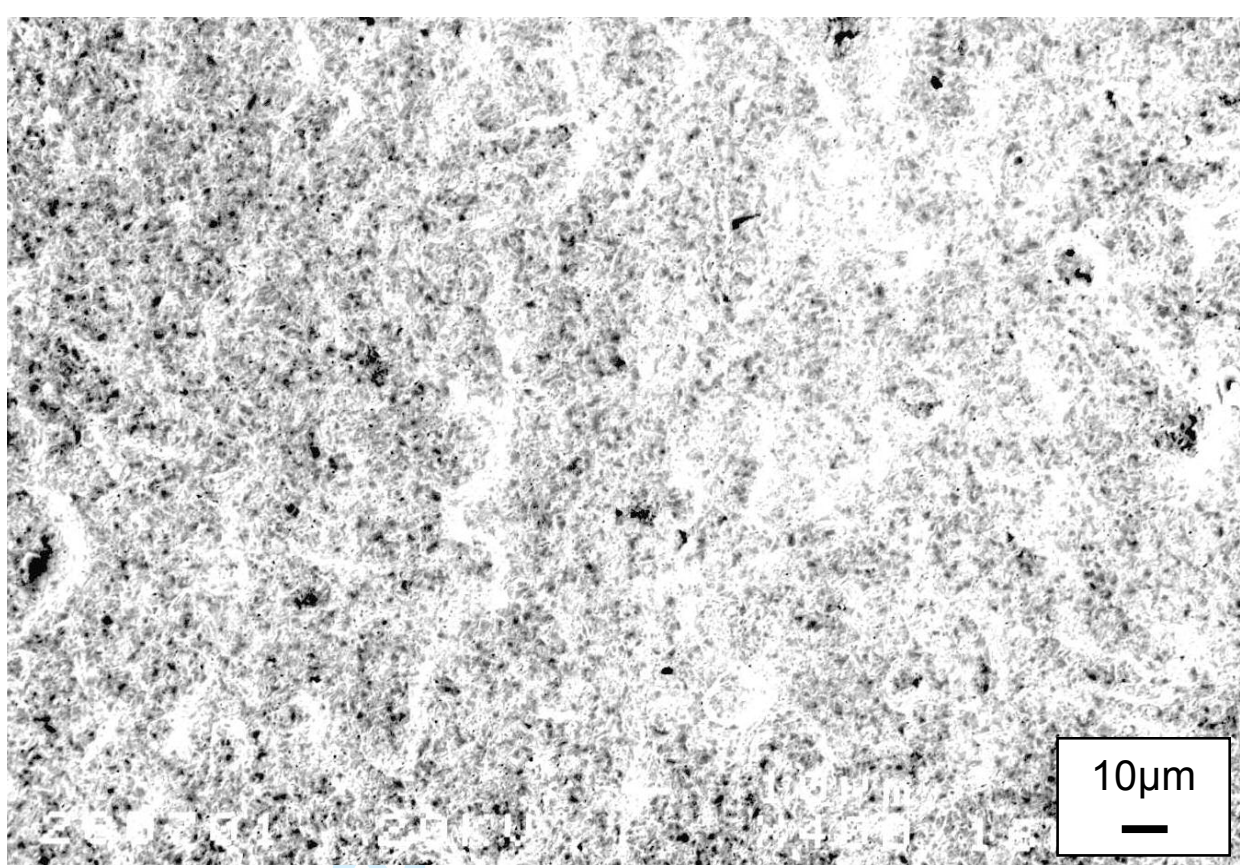

Fig. 10: Micrograph of the nucleation surface of a $60 \mu \mathrm{m}$ diamond coating, tested at $268 \mathrm{~m} \mathrm{~s}^{-1}$ for 5 hours following dissolution of the tungsten substrate. This area was away from the area of particle impact. The white appearance is due to the presence of a layer of residual tungsten approximately $10 \mu \mathrm{m}$ thick. 


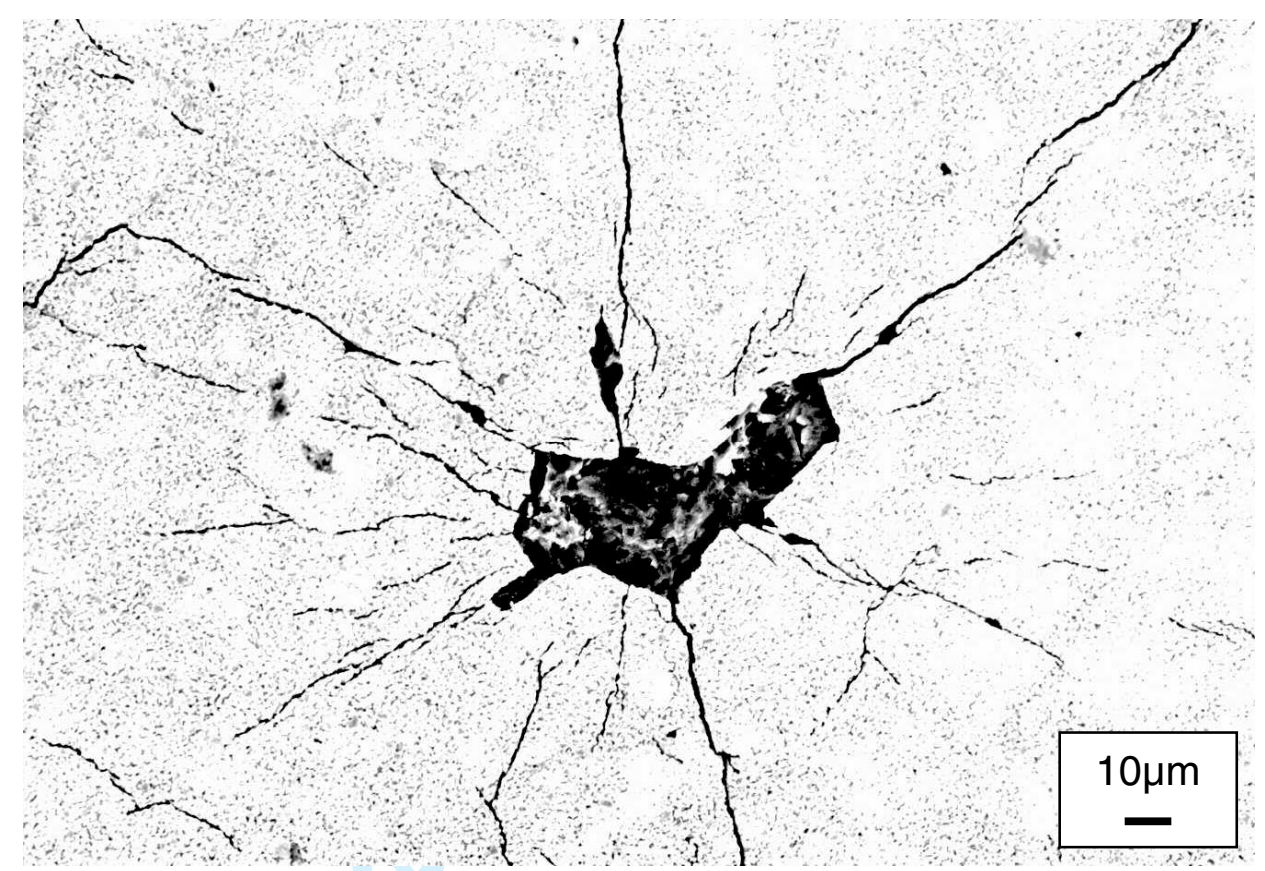

Fig. 11: Micrograph of the nucleation surface of the same sample as Figure 10, showing cracks propagating away from a tungsten-free area, which was thought to have been a delaminated region of the coating prior to dissolution of the substrate. 
Fig. 12: Micrograph of the nucleation surface of a $60 \mu \mathrm{m}$ diamond coating, tested at $268 \mathrm{~m} \mathrm{~s}^{-1}$ for 5 hours showing a pin-hole that has completely penetrated the coating surrounded by tungsten-free diamond. 


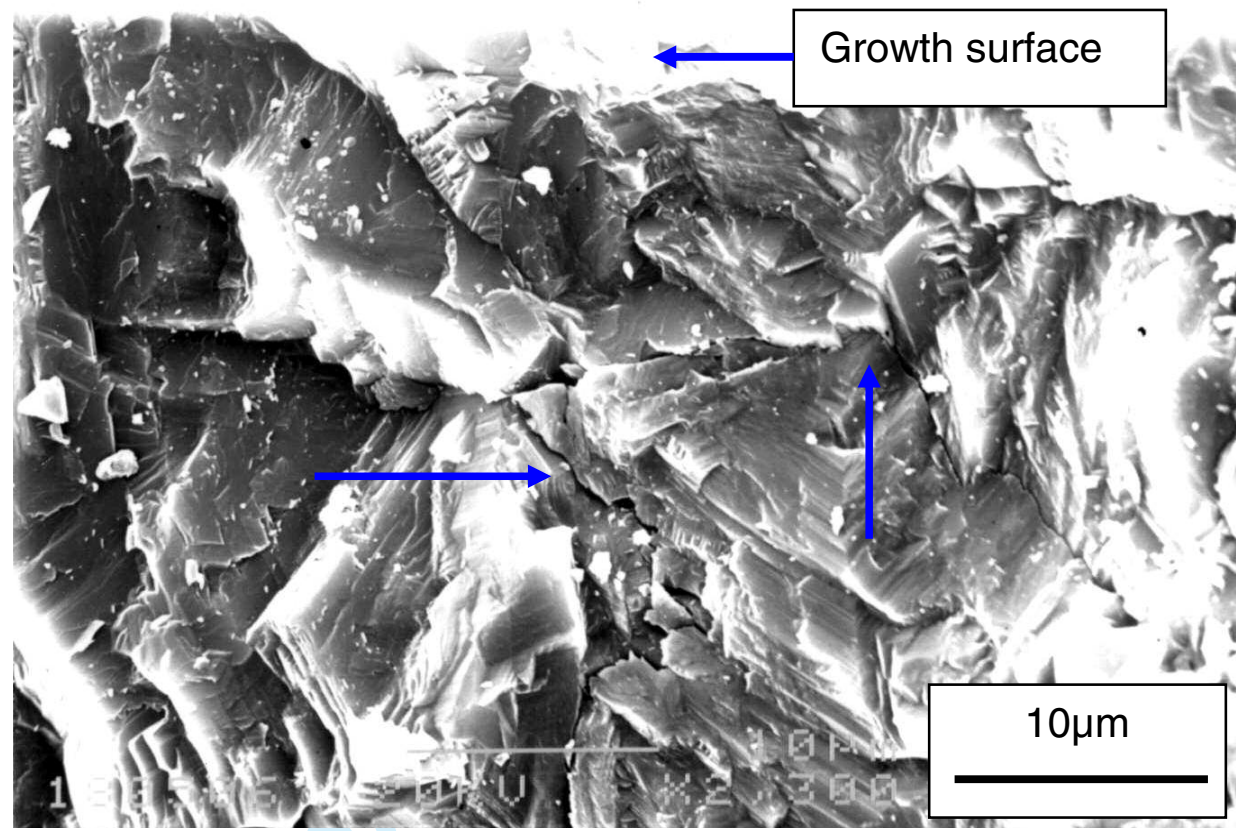

Fig. 13: Micrograph of a transverse section of the $60 \mu \mathrm{m}$ coating shown in Figures 10 to 12 showing a circumferential crack (arrowed) extending through the coating in the direction of the coating-substrate interface. The crack can also be seen branching into two at a depth of approximately $15 \mu \mathrm{m}$. 